\title{
ANALYSIS OF STANDARD PROBLEM SIX (SEMISCALE TEST S-02-6) DATA
}

\author{
CHARLES E. CARTMILL
}

August 1977

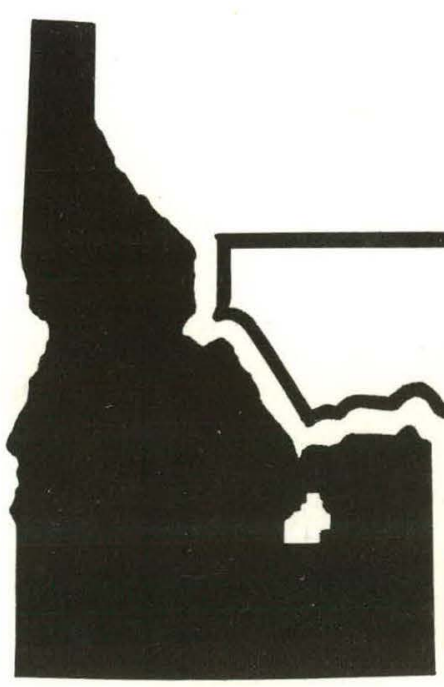

EG\&G Idaho, Inc.

IDAHO NATIONAL ENGINEERING LABORATORY

ENERGY RESEARCH AND DEVELOPMENT ADMINISTRATION

IDAHO OPERATIONS OFFICE UNDER CONTRACT EY-76-C-07-1570 


\section{DISCLAIMER}

This report was prepared as an account of work sponsored by an agency of the United States Government. Neither the United States Government nor any agency Thereof, nor any of their employees, makes any warranty, express or implied, or assumes any legal liability or responsibility for the accuracy, completeness, or usefulness of any information, apparatus, product, or process disclosed, or represents that its use would not infringe privately owned rights. Reference herein to any specific commercial product, process, or service by trade name, trademark, manufacturer, or otherwise does not necessarily constitute or imply its endorsement, recommendation, or favoring by the United States Government or any agency thereof. The views and opinions of authors expressed herein do not necessarily state or reflect those of the United States Government or any agency thereof. 


\section{DISCLAIMER}

Portions of this document may be illegible in electronic image products. Images are produced from the best available original document. 
Printed in the United States of America

Available from

National Technical Information Service

U.S. Department of Commerce

5285 Port Royal Road

Springfield, Virginia 22161

Price: Printed Copy $\$ 4.50$; Microfiche $\$ 3.00$

"The NRC will make available data tapes and operational computer codes on research programs dealing with postulated loss-of-coolant accidents in light water reactors. Persons requesting this information must reimburse the NRC contractors for their expenses in preparing copies of the data tapes and the operational computer codes. Requests should be submitted to the Research Applications Branch, Office of Nuclear Regulatory Research, Nuclear Regulatory Commission, Washington, D.C. 20555."

\section{NOTICE}

This report was prepared as an account of work sponsored by the United States Government. Neither the United States nor the Energy Research and Development Administration, nor the Nuclear Regulatory Commission, nor any of their employees, nor any of their contractors, subcontractors, or their employees, makes any warranty, express or implied, or assumes any legal liability or responsibility for the accuracy, completeness or usefulness of any information, apparatus, product or process disclosed, or represents that its use would not infringe privately owned rights. 
TREE-NUREG-1056

ANALYSIS OF STANDARD PROBLEM SIX

(SEMISCALE TEST S-02-6) DATA

Approved:

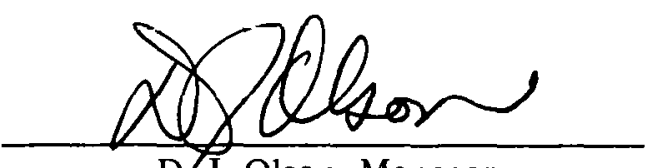

D/J. Olson, Manager

Semiscale Program

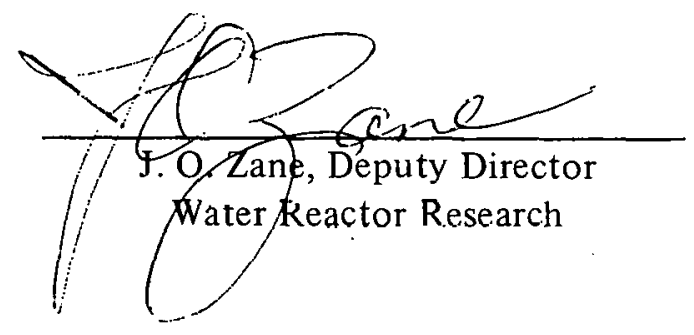

This report was prepared as an account of work sponsored by the United States Covernment. Neither Research and Development Administration, nor any of their emplnyees, nos ony of theis wiltactiurs, subcontractors, of their employees. makes any warranty, express or implied, or assumes any legal

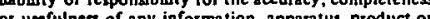

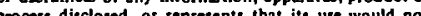
process disclosed, or represents
infringe privately owned rights. 


\title{
ANALYSIS OF STANDARD PROBLEM SIX \\ (SEMISCALE TEST S-02-6) DATA
}

\author{
by
}

Charles E. Cartmill

EG\&G IDAHO, INC.

August 1977

\author{
PREPARED FOR THE \\ U.S. NUCLEAR REGULATORY COMMISSION \\ AND \\ ENERGY RESEARCH AND DEVELOI'MENT ADMINISTRATION \\ IDAHO OPERATIONS OFFICE \\ UNDER CONTRACT NO. EY-76-C-07-1570
}




\section{ACKNOWLEDGMENTS}

The author expresses his appreciation to the personnel of the Semiscale Facilities and

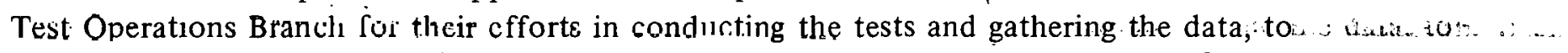
the pcrsonnel of the Test. Fingineering Branch for duciimentation of the data, tn D. G. Hall and M. D. Zentner for contributing the technical support, and to ' 1 '. K. Larson for supplying posttesst calculations. 


\begin{abstract}
Test S-02-6 of the Semiscale Mod-1 blowdown heat transfer test series was conducted to supply data for the U.S. Nuclear Regulatory Commission Standard Problem Six. To determine the credibility of the data and thus establish the validity of Standard Problem Six, an analysis of the results of Test S-02-6 was performed and is presented. This analysis consisted of investigations of system hydraulic and core thermal data. The credibility of the system hydraulic data was investigated through comparisons of the data with data and calculations from related sources (Test S-02-4) and, when necessary, through assessment of physical events. The credibility of the core thermal data was based on a thorough analysis of physical events. The results of these investigations substantiate the validity of Test S-02-6 data.
\end{abstract}




\section{SUMMARY}

The Semiscale Mod-1 Program was designed to investigate the behavior of a pressurized water reactor system (PWR) model during an hypothesized loss-of-coolant accident (LOCA). The Mod-l system is a scaled down model of a PWR that simulates the principal physical features of a nuclear plant, and is designed such that all facets of the accident may be investigated. Nuclear heating is simulated in the tests by a core composed of an array of electrically heated rods. The core is contained in a pressure vessel which also includes a downcomer, lower plenum, and upper plenum. The system piping is arranged in a 1-1/2-loop configuration with the broken loop containing passive simulators for the steam generator and pump.

I'est S-02-6 uf the Scmisoale Mod-1 blowdnwn heat transfer test series was conducted to supply thermal-hydraulic data concerning the fluid phenomena that occur as a result of a small break. Although, due to the not totally representative single-ended break geometry, the phenomena occurring in the broken loop are not considered typical of those that might occur in a PWR, evaluation of the thermal-hydraulic response of the Scmiscale system can be valuable in characterizing of the most significant thermal-hydraulic phenomena likely to occur in the primary coolant system of a PWR during the slow depressurization (blowdown) and emergency core cooling (ECC) phases of a small break LOCA. The data are to be used for the U.S. Nuclear Regulatory Commission (NRC) Standard Problem Six. The NRC standard problem tests are tests conducted to establish an experimental data base for the purpose of comparison with unbiased analytical calculations supplied by the standard problem program participants. The standard jioblems provide a means of evaluating the adequacy of system models used to predict the overall thermal-hydraulic response of a particular system during a bluwdown transicnt. The results of Semiscale Test S-02-6 were withheld from the standard problem program participants until their analylical predictions had been coinpleted.

The Semiscale Mod-1 system was arranged in a cold leg break configuration for Test S-02-6. The procedure followed in the approach lo the test was: (a) the system was brought up to pressure ( $2265 \mathrm{psig}$ ), desired flow rate, and temperature of about $542^{\circ} \mathrm{F}$; (b) core pnwer was increased in successive steps to about $1.6 \mathrm{MW}$; (c) core power and core flow rate were adjusted to attain the desired core differential temperature of about $67^{\circ} \mathrm{F}$ and the system was allowed to equilibrate; and (d) after the desired initial steady state conditions hud been attained, the system was subjected to decompression by introducing a leak in the broken loop cold leg. As the test proceeded, emergency core coolant (ECC) was injectcd in to the in tact and broken loop cold legs.

Test S- $02-6$ represented a simulated small $(6 \%)$ single-ended break which resulted in a much longer subcooled blowdown period (63 sec compared with about $3 \mathrm{sec}$ for a $200 \%$ break), and a much slower depressurization (system pressure of 600 psig occurring at $290 \mathrm{sec}$ instead of at $17 \mathrm{sec}$ for a $200 \%$ break) of the system. The period of time from the end of subcooled flow $(63 \mathrm{sec})$ to the time of emergency core coolant injection $(290 \mathrm{sec})$ 
was uneventful because all significant dynamic effects were completed by the time the subcooled blowdown was complete and because the core thermal response was such that the temperature of all of the rods was below $600^{\circ} \mathrm{F}$ at the beginning of saturated blowdown.

A pump suction seal formed during blowdown and the resulting phenomena relating to the pump seal blowout that occurred in the pump suction leg piping were as expected, that is, the seal remained until the core liquid level dropped below the lower elevation of the pump suction leg at which time the seal blew out.

Core temperatures above the initial operating temperature did not occur during Test S-02-6, and emergency core coolant injection was sufficient to cool the core and keep it covered during the latter portion of the test. In the Semiscale system the small break did not result in a rod thermal behavior as severe as observed in the large break tests and thus the small break experiment represents a less severe loss-of-coolant experiment. 
CONTENTS

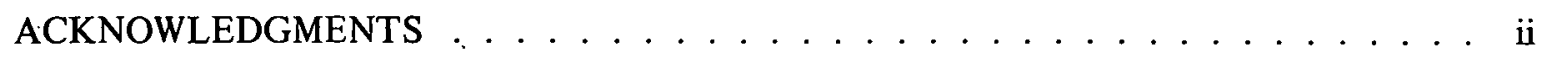

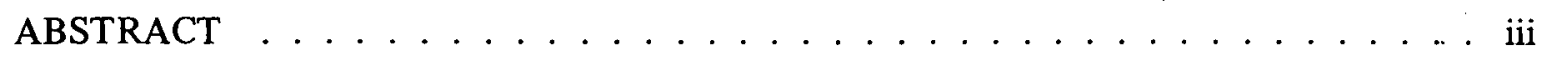

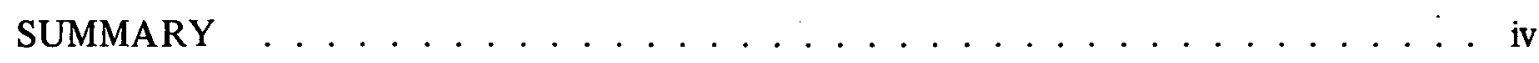

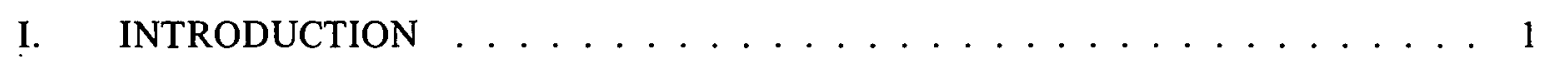

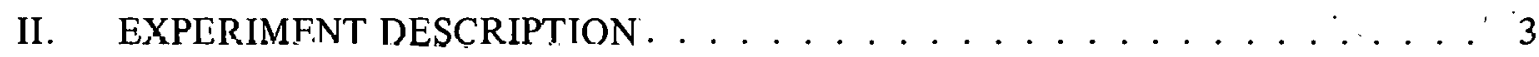

1. SYSTEM HARDWARE DESCRIYIIUN ............... . 3

2. POWER AND POWER CONTROL ................. 4

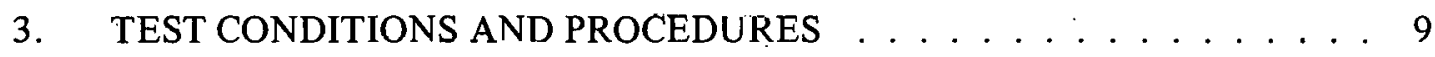

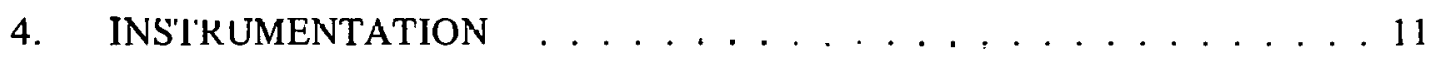

III. OVERALL THERMAL-HYDDAULIC BEHAVIOR DURING BLOWDOWN . . . 13

1. HYDR.ATIIIIC PHENOMENA OCCURRING AT THE BREAK . . . . . . . 13

2. FLUID BEHAVIOR GOVERNEN BY PUMP SUCTION PHENOMENA . . 16

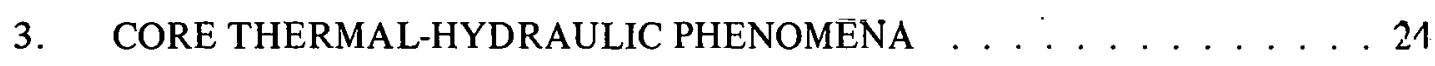

4. HYDRAULIC PHENOMENA OCCURRING IN THE VESSEL

FOLLOWING INITIATION OF ECC . . . . . . . . . . . . . . 27

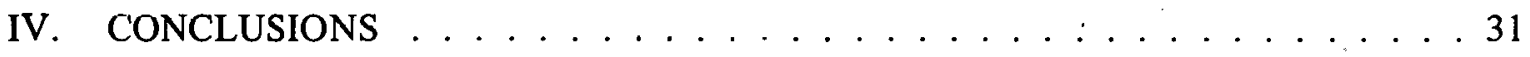

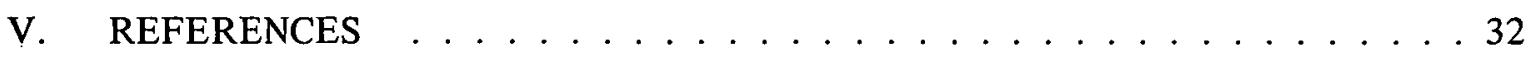

ÅPPENDIX A - S"IEAM GENERATUR RESPONSE . . . . . . . . . . . . 33

APPENDIX B - PIPING HEAT TRANSFER . . . . . . . . . . . . . . 39 


\section{FIGURES}

1. Semiscale configuration for Test S-02-6 .............. . . 4

2. Semiscale Mod-1 electric heater rod . . . . . . . . . . . . . 5

3. Cross section of vessel with core ................... . . 6

4. Vessel cross section and core layout . . . . . . . . . . . . . 7

5. Semiscale Mod-1 axial power profile ................ 8

6. Core transient power - Test $\mathrm{S}-02-6 \ldots \ldots \ldots \ldots$

7. Semiscale Mod-1 heated core configuration showing locations

of heater rod thermocouples . . . . . . . . . . . . . . . . . 11

8. Comparison of mass flow rates for small break Test S-02-6

and $200 \%$ break Test S-02-4 . . . . . . . . . . . . . . . . . . 14

9. Comparison of pressures at the break for small break

Test S-02-6 and $200 \%$ break Test S-02-4 . . . . . . . . . . . . 15

10. Mass flow rates at the core inlet and at intact and broken

loop cold legs $-\mathrm{S}-02-6 \ldots \ldots \ldots \ldots$. . . . . . . . . . . . . . . . . . . .

11. Fluid temperatures at the break vcrsus saturation

temperature - Test S-02-6 . . . . . . . . . . . . 16

12. Illustration of pump suction seal - Test S-02-6 .......... 17

13. Fluid densities at the intact loop hot leg - Test S-02-6 . . . . . . . 18

14. Fluid temperatures on each side of the steam generator -

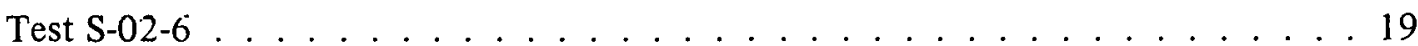

15. Mass flow rates at the core barrel inlet and inlact loop cold leg - Test S-02-6 . . . . . . . . . . . . . . . . . . 19

16. Collapsed liquid levels in the downcomer and core from differential pressure measurements - Test $\mathrm{S}-02-6 \ldots \ldots$. . . . . . . . 20

17. Illustration of system hydraulic condition at $40 \mathrm{sec}-$

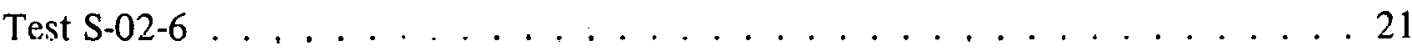


18. Illustration of system hydraulic condition at $50 \mathrm{sec}-$

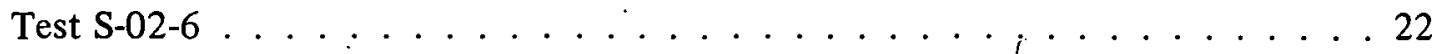

19. Illustration of system hydraulic condition at $60 \mathrm{sec}-$ Test S-02-6 . . . . . . . . . . . . . . . . . . . . 23

20. Illustration of system hydraulic condition at $100 \mathrm{sec}-$ Test S-02-6 . . . . . . . . . . . . . . . . . . . 24

21. Core temperature response $(\operatorname{Rod} \mathrm{F} 6)-\mathrm{Test} \mathrm{S}-02-6 \ldots \ldots 25$

22. Semiscale Mod-1 heated core configuration showirng radial locations where rods experience different tcmporature response . . . . . . . . 26

23. Fluid density in system piping - Test $\mathrm{S}-02-6 \ldots \ldots 27$

24. Intact loop cold leg fluid temperatures - Test $\mathrm{S}-02-6 \ldots \ldots 28$

25. Upper plenum system pressure - Test $\mathrm{S}-02-6 \ldots \ldots$. . . . . . . . . . . 29

26. Intact loop cold leg volumetric flow rate - Test S-02-6 . . . . . . . . . . 29

27. Intact loop hot leg and pump inlet volumetric flow rates -

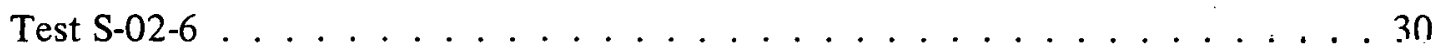

A-1. Intact loop steam generator configứration $\ldots \ldots \ldots$

A-2. Steam generator secondary side fluid tcmperatures Test S-02-6 . . . . . . . . . . . . . . . . . . . 37

A-3. Steam generator secondary side metal temperatures -

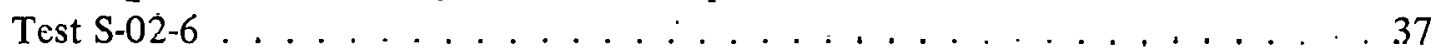

A-4. Steam generator primary and secondary side fluid temperatures - Test $3=02-6 \ldots \ldots \ldots$. . . . . . . . . . . . . . . . . .

B-1. Intact and broken loop cold leg surface heat fluxes Test S-02-6 . . . . . . . . . . . . . . . . . . 42

B-2. Vertical and horizontal fluid densities in instrument Spool 15 - Test S-02-6 


\section{TABLE}

I. Description of Blowdown Heat Transfer Test S-02-6,

U.S. Nuclear Regulatory Commission Standard Problem Six . . . . . . . . . . 10 


\title{
ANALYSIS OF STANDARD PROBLEM SIX
}

\author{
(SEMISCALE TEST S-02-6) DATA
}

\section{INTRODUCTION}

The Semiscale Mod-1 experimental program conducted by EG\&G Idaho, Inc. is part of the overall U.S. Nuclear Regulatory Commission (NRC) and Energy Research and Development Administration-sponsored research and development program to investigate the behavior of the pressurized water reactor (PWR) system during an hypothesized loss-of-coolant accident (LOCA). The Semiscale Mod-1 program is intended to provide transient thermal-hydraulic data from a simulated LOCA using a small scale experimental nonnuclear system. The Semiscale Mod-1 program is a major contributor of experimental data that provide a means of evaluating the adequacy of the overall system analytical models as well as the models of the individual system components. Selected experimental data produced by this program will also be used to aid other Energy Research and Development Administration-Nuclear Regulatory Commission-sponsored experimental programs, such as the Loss-of-Fluid Test (LOFT) program ${ }^{[1]}$, in optimizing test series, selecting test parameters, and evaluating test results.

The Semiscale Mod-1 tests are performed with an experimental system which simulates the principal physical features of a nuclear plant but which is smaller in volume. Nuclear heating is simulated in the tests by a core composed of an array of electrically heated rods. The core is contained in a pressure vessel which also includes a downcomer, lower plenum, and upper plenum. The Semiscale system piping is arranged such that the intact loop represents three loops of a four-loop nuclear plant, and the broken loop represents the fourth loop. In the present configuration the intact loop contains an activc steam generator and pump, and the broken loop contains passive simulators for the steam generator and pump.

Test S-02-6 was a small (6\%) single-ended break test which was conducted as part of the blowdown heat transfer test series (Test Series 2 of the Semiscale Mod-1 Program). The purpose of Test S-02-6 was to supply thermal-hydraulic information concerning the fluid phenomena that occur as a result of a small break. Although, due to the not totally representative single-ended break geometry, the phenomena occurring in the broken loop are not considered typical of those that might occur in a PWR, evaluation of the thermal-hydraulic response of the Semiscale system can be valuable in characterizing of the most significanl thermal-hydraulic phenomena likely to occur in the primary coolant system of a PWR during the slow depressurization (blowdown) and emergency core cooling (ECC) phases of a small break LOCA. Test S-02-6 served as the Nuclear Regulatory Commission 
Standard Problem Number Six ${ }^{[a]}$. The specific objectives of this small break test were to determine (a) the general system thermal-hydraulic behavior during the slow depressurization that occurs as a result of the small break, (b) the general core temperature response, and whether the immersed core becomes uncovered during a small break, and (c) the effectiveness of the emergency core cooling (ECC) systems for a small break condition.

Analyses of the data from other tests performed in the blowdown heat transfer series are presented in References 2 through 6. This report presents the results of analysis performed to evaluate the observed core and loop piping thermal-hydraulic response of the Semiscale Mod-1 system. Discussions concerning the general system thermal-hydraulic behavior occurring during blowdown are presented. Specific fluid phenomena occurring at the break, within the pump suction leg, and in the core rcgion, are also presented. Core and loop response calculations that were obtained through computer code models are used.to explain experimental data. Soction II of this repurt contains a dcscription of the Semiscale Mnd-1 system and the test plan followed for the small break Test S-02-6. The results of the analysis of the blowdown data are presented in Scction III. Section III rmitains a discussion. of the overall thermal-hydraulic behavior during blowdown, with emphasis placed on the break phenomena. The significant conclusions concerning the results from the small break test are presented in Section IV.

[a] The objective of the standard problem program is to provide a mechanism to systematically increase the participants' understanding and knowledge of the computational techniques used to analyze the performance of nuclear power reactors. Facilities such as Semiscale provide the experimental data used in assessing and verifying the computational techniques. 


\section{EXPERIMENT DESCRIPTION}

The Semiscale Mod-1 experimental system and test plan for Test S-02-6 of the blowdown heat transfer test series are described. The topics discussed include the overall system hardware, power and power control, test conditions and procedures, and instrumentation.

\section{SYSTEM HARDWARE DESCRIPTION}

The Semiscale Mod-1 experimental apparatus is a small scale model of the Loss-of-Fluid Test (LOFT) system ${ }^{[1]}$ which is in turn a $55 \mathrm{MW}(\mathrm{t})$ test reactor model of a four-loop pressurized water reactor. The Semiscale system, which has a liquid volume of approximately $7.8 \mathrm{ft}^{3}$, consists of a pressure vessel and internals; an intact loop consisting of a pressurizer, steam generator, and coolant pump; and a broken loop with hydraulic resistances that simulate an inactive stcam generator and a locked rotor pump.

The Semiscale Mod-1 system was modified from its normal configuration in order to provide a test which would represent a $6 \%$ break in a four-loop PWR for the small cold leg break and is shown in its modified configuration in Figure 1. These modifications included the addition of a longer intact loop pump suction leg and the deletion of the broken loop hot leg; the vessel was capped off at the hot leg outlet. The elevation of the low point of the intact loop pump suction leg (normally $41 \mathrm{in}$. below the cold leg centerline) was lowered to about $100 \mathrm{in}$. below the cold leg centerline. This lower elcvation alluws the percentage of core length between the top of the core and the bottom of the pump suction elevation to be cssentially the same in the Semiscale system as it is in a PWR. The pump suction leg was lowered so that the percent of the core uncovered in Semiscale would more closely represent that percentage of the core uncovered in a PWR during a postulated small break accident. The broken loop hot leg was removed to better represent a single-ended hreak, and to eliminate the additional cunplexity of data analysis that would have resulted had the broken loop hot leg been left in the system. A complete description of the unmodified Semiscale system is given in Reference 7.

Emergèncy core coolant was injected during the small break experiment by three separate ECC systems: high pressure injection system (HPIS), low pressure injection system (LPIS), and gas pressurized water accumulator system. 


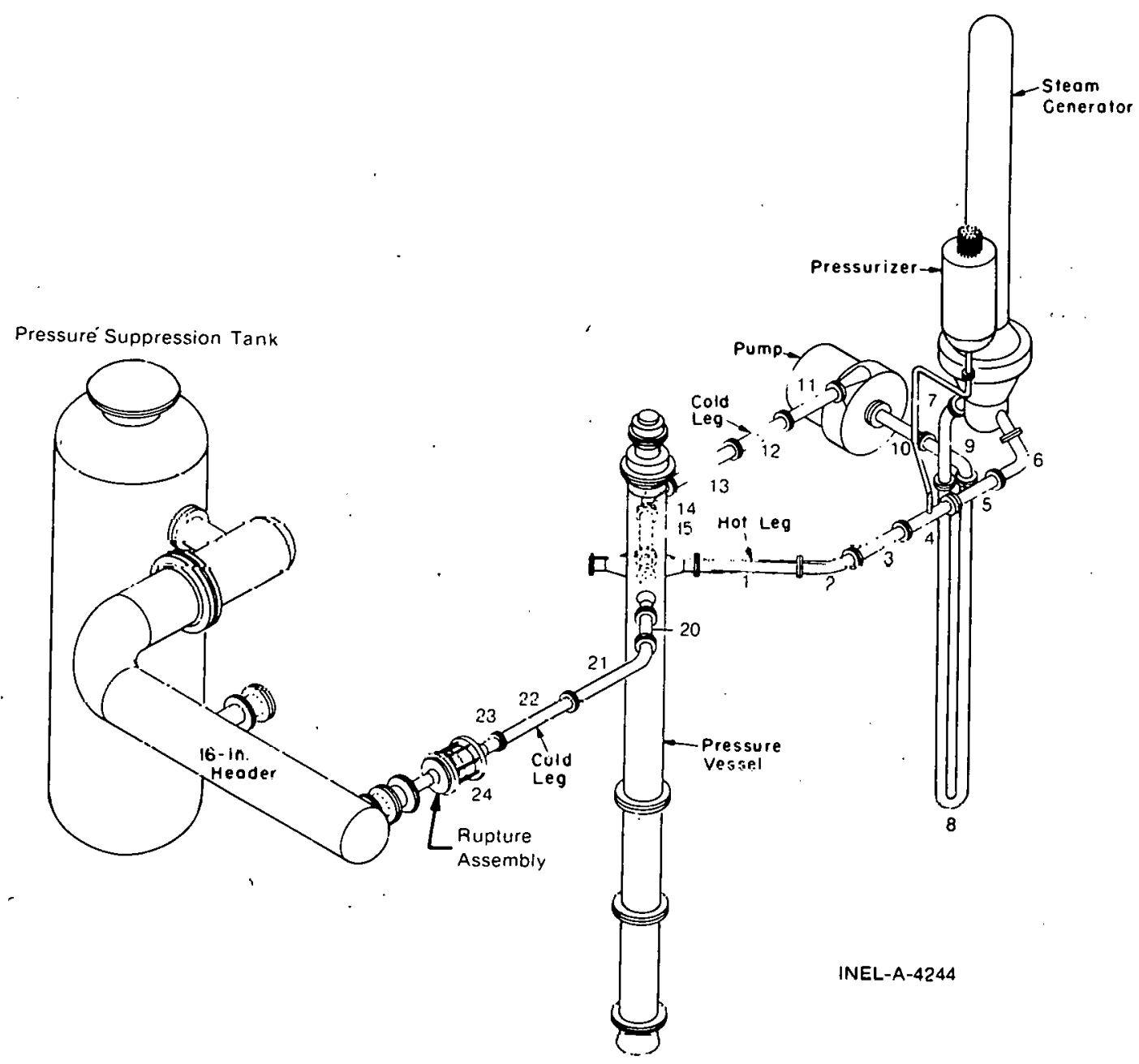

Fig. 1 semiscuale cunfiguration for Test S-n? -6.

\section{POWER $\Lambda$ ND POWFR CONTROL}

The core simulator in the Semiscale systent consistod of 40 elpsitrically heated rods of typiral PWR fuel rod diameter (0.422 in.) and axial power peaking factor (1.58). Figure 2 illustrates the general construction of a Semiscale heater rud. The ovcrall length of the rod is 207 in., and the bottom of the 5.5-foot healed section 1s abuut 143 in. helow the vessel cold leg centerline as shown in Figure 3. The rods extend from the bottom of the heated section to the upper plenum and pass out through the vessel uppcr head.

The 40 rods are positioned and letd in the core with 10 grid spacers which maintain the heaters on a typical PWR pitch (0.563 in.). Figure 4 shows a plan vicw of the Semiscale vessel and core simulator assembly. A heat shield assembly composed of 0.018 -in.-thick stainless steel surrounds the rod matrix and reduces the core flow area to $7.39 \mathrm{in} .^{2}$. The four centrally located rods (the high power rods) can be powered at a level which is different 


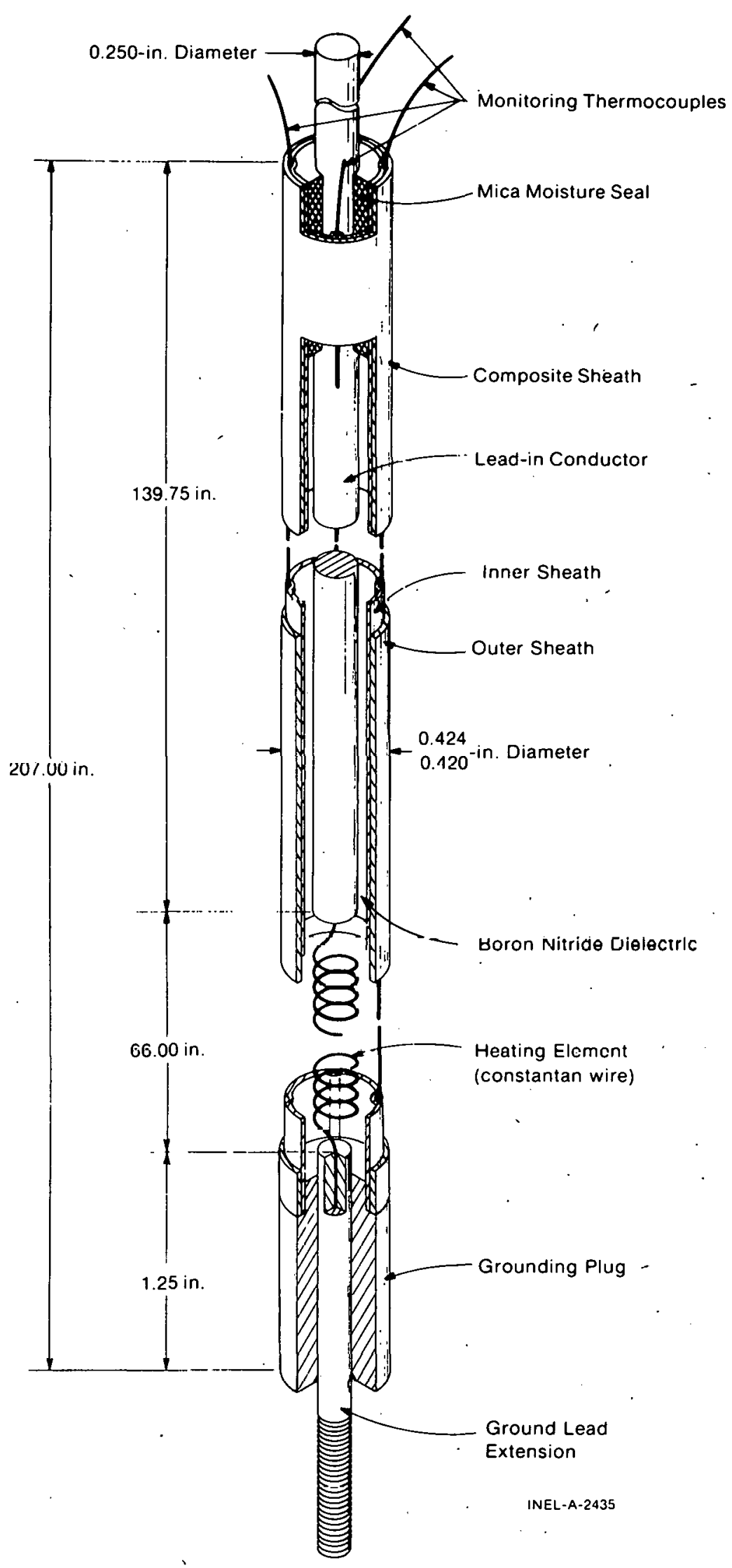

Fig. 2 Scmiscale Mod-1 electric heater rod. 


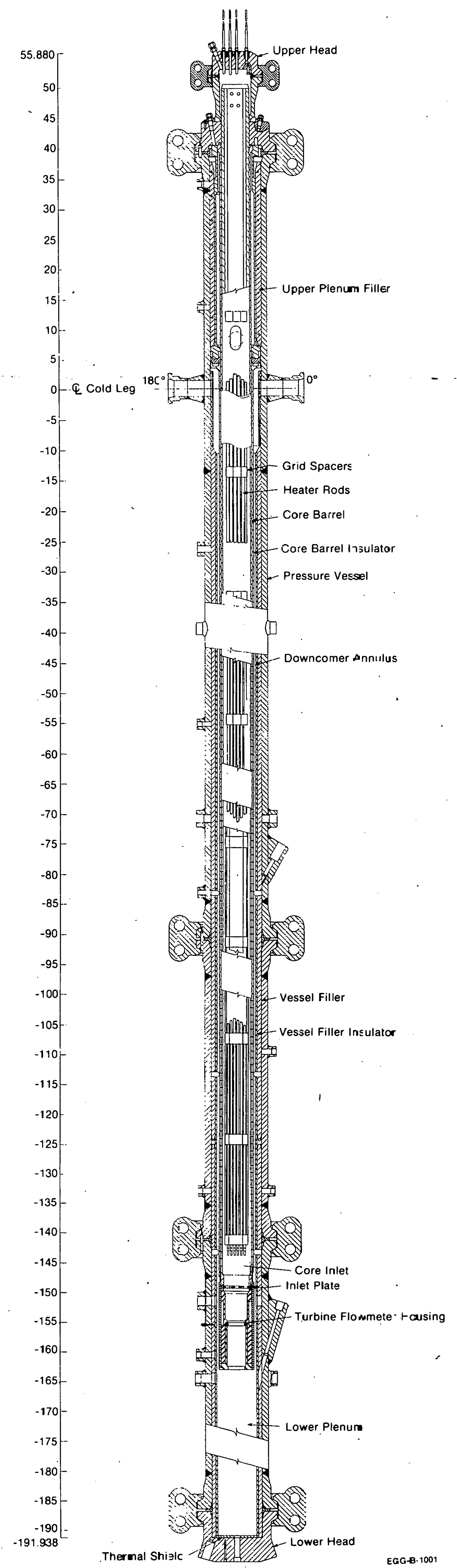




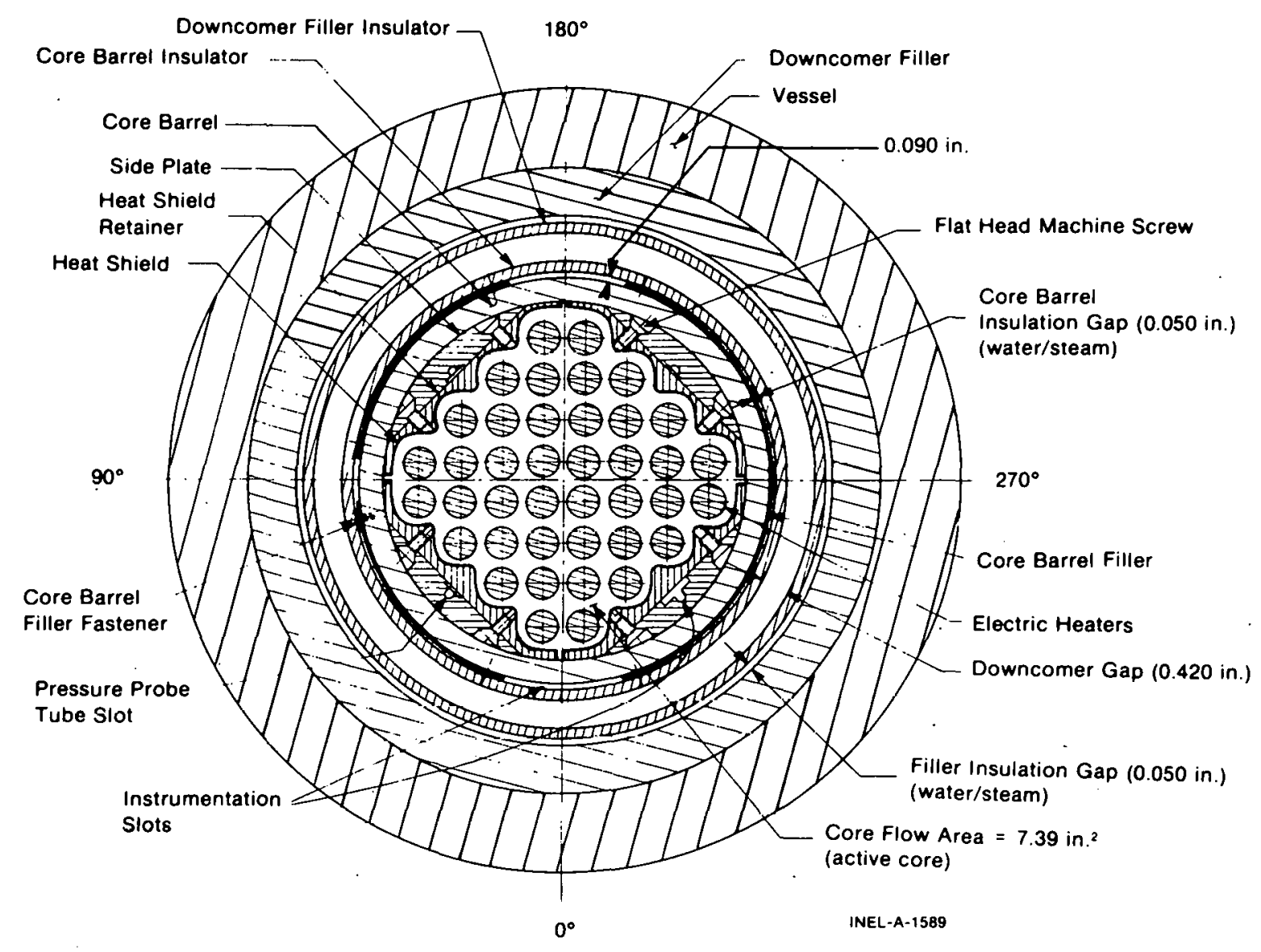

Fig. 4 Vessel cross section and core layout.

than the remaining 36 rods (the low power rods). This method of powering the heater rods allows the simulation of radial peaking similar to that which exists in a nuclear core. Test S-02-6 had a radially peaked power profile; the center four rods had an initial peak power density of $14.25 \mathrm{~kW} / \mathrm{ft}$ and the surrounding powered rods had a peak power density of $11.54 \mathrm{~kW} / \mathrm{ft}$ providing a total core power of $1.56 \mathrm{MW}$. Tlıe axial power profile tor the as-constructed rods is illustrated in Figure 5.

Figure 6 shows the transient electrical core power used during Test 3-02-6. This electrical power was determined by analytically matching the surface heat flux calculated for an electrical rod to the surface heat flux calculated for a nuclear rod, assuming that both rods were subjected to the same transient boundary.conditions as described in Reference?. 


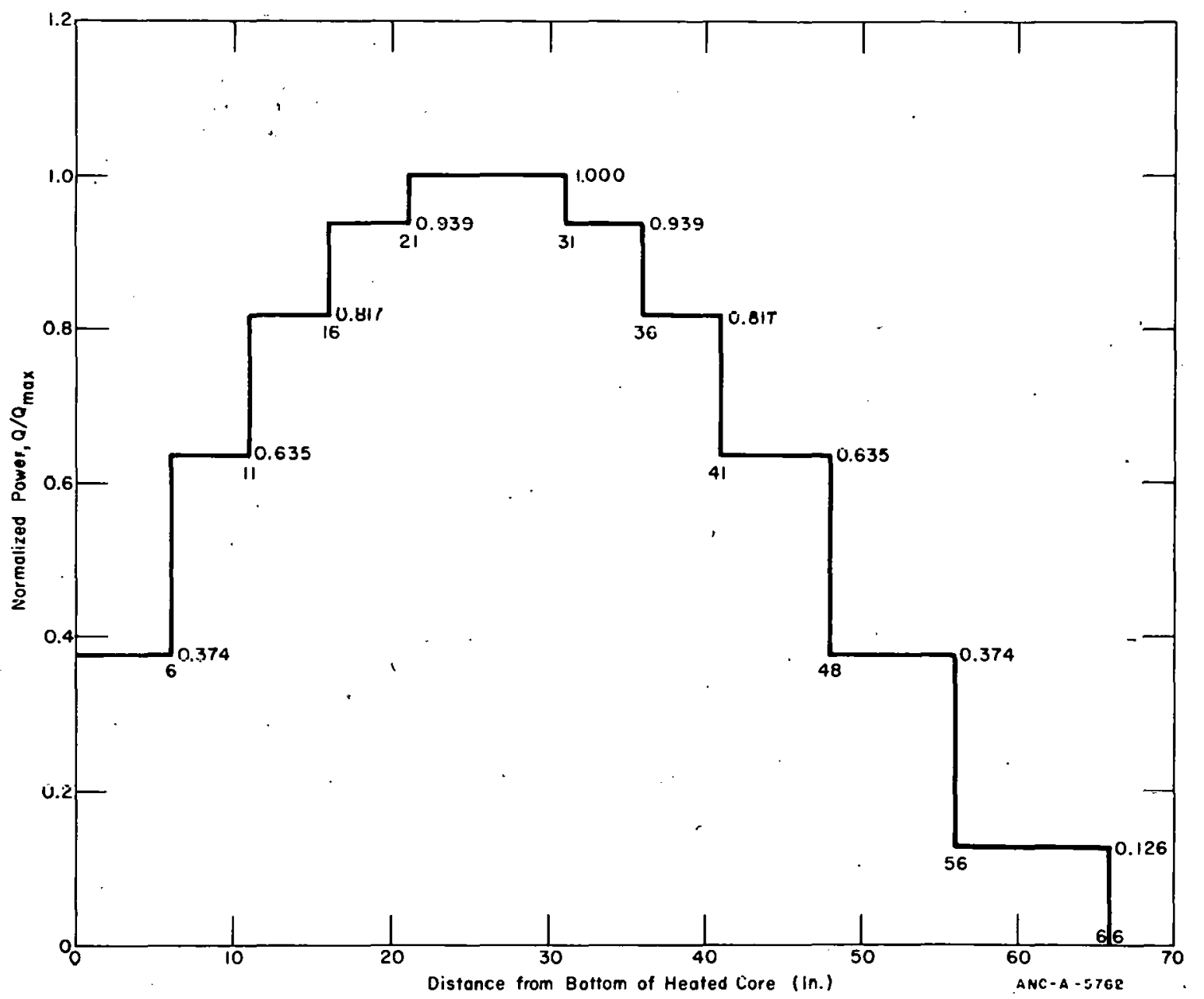

Fig. 5 Semiscale Mnd-1 axial power profile. 


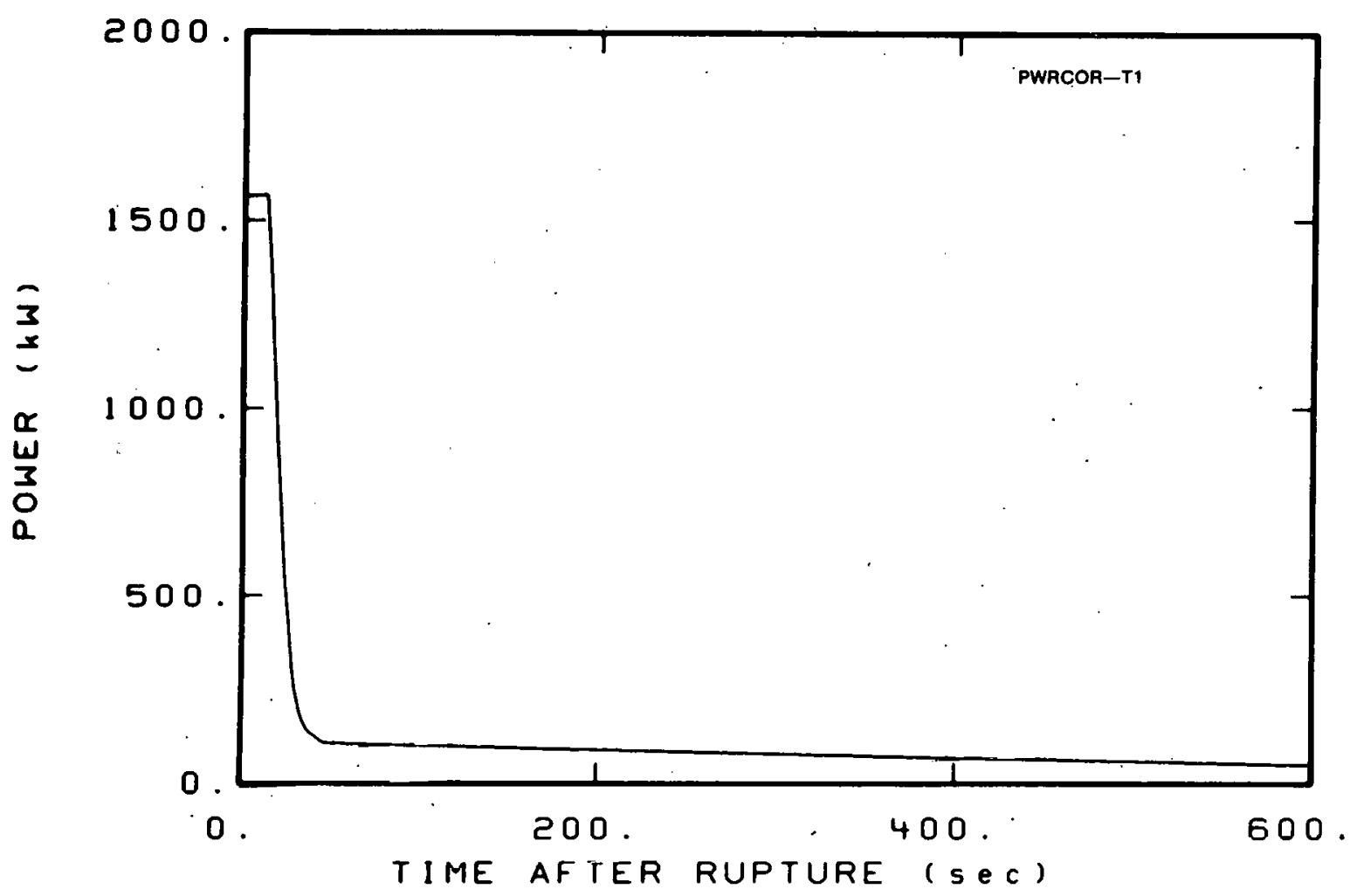

Fig. 6 Core transient power - Test S-02-6.

\section{TEST CONDITIONS AND PROCEDURES}

Table I presents an overview of the test conditions and other pertinent information relating to the blowdown heat transfer Test S-02-6.

The basic procedure followed in the approach to rupture initiation in Test S-02-6 was as follows: (a) the system conditions were established at a pressure of 2265 psig, flow rate of $148 \mathrm{gpm}$, and a temperature of $542^{\circ} \mathrm{F}$; (b) the core power was increased to the desired value in successive steps; (c) the core power and flow rate were adjusted to achieve a core differential temperature of $67^{\circ} \mathrm{F}$ and the system was allowed to equilibrate. After the initial steady state conditionis had been achieved, blowdown was initiated by introducing a leak in the system piping by means of a rupture assembly. 
DESCRIPTION OF BLOWDOWN HEAT TRANSFER TEST S-02-6, U.S. NUCLEAR REGULATORY COMMISSION STANDARD PROBLEM SIX

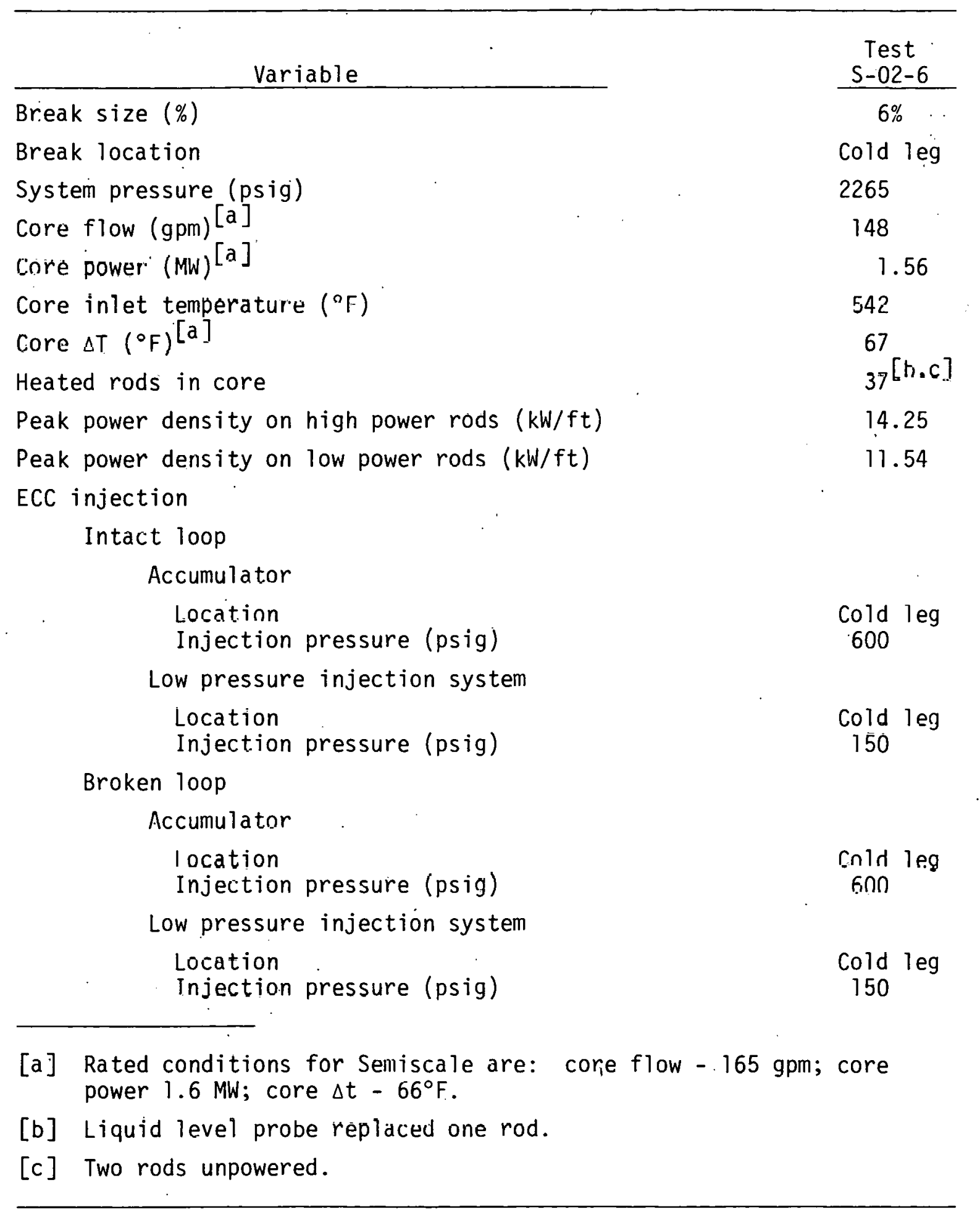




\section{INSTRUMENTATION}

A description and listing of the instrumentation used in the Semiscale system for Test S-02-6 is included in Reference 8. Of particular concern to standard problem participants are the instrumentation measurements taken within the core region, specifically with respect to the heater rods. Figure 7 illustrates the heater rod matrix and cladding thermocouple locations for the core rod temperature measurements. The heater rods are identified within the matrix by reference to the row of letters across the top and the column of numbers

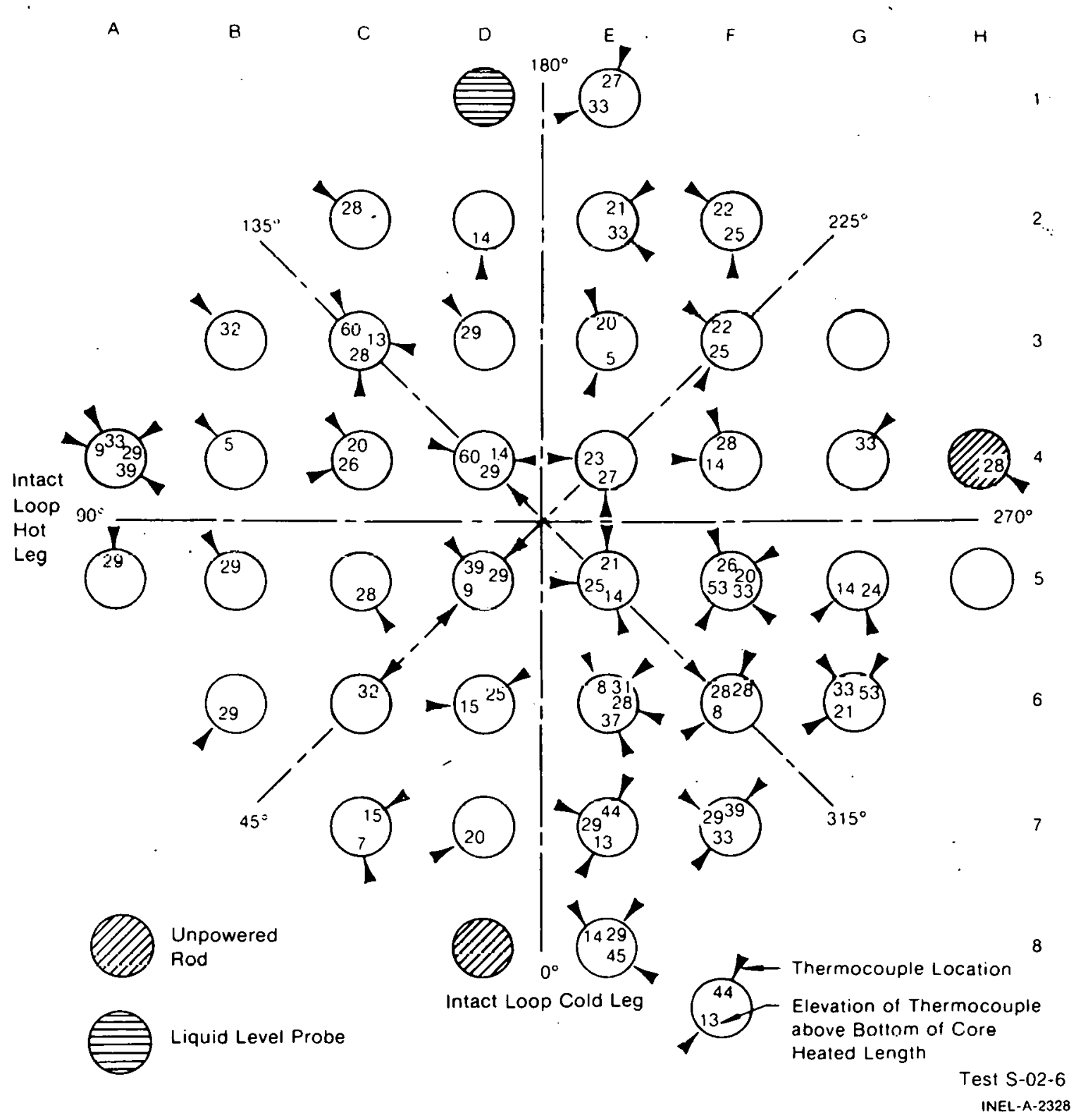

Fig. 7 Scmiscale Mud-1 heated core configuration showing lncations of heater rod theirnocouples. 
down the side of the matrix. Similarly, the thermocouples are identified by the rod that they are on and by their elevation above the bottom of the heated length of the core. The thermocouple on Rod D5 at the 29-in. elevation is thus referred to as TH-D5-29 where TH refers to a core heater cladding temperature, D5 refers to the rod upon which the thermocouple is located, and 29 gives the thermocouple elevation in inches above the core bottom. (The arrows in Figure 7 indicate thermocouple azimuthal locations.)

Core measurements taken in addition to the heater rod cladding temperatures included core voltage, power, current, fluid temperature, inlet flow, and inlet density. Electrical current was measured using a shunt circuit technique, and voltage was obtained from a digital voltmeter. The voltage and current measurements were processed through a Hall-effect multiplier to obtain the total core power. Core inlet flow rate and fluid density measurements were provided by instrumentation consisting of a turbine flowmeter, drag diso flowmeter, and gamma densitometer located beluw the bottom of the heater rods Core fluid temperatures were measured with thermocouples attached to the grid spacers located along the heated length of the rods.

Measurement of test variables other than within the vessel was accomplished by detectors located within the intact and broken loop piping. Detectors were provided for measuring fluid and material temperatures, pressure, differential pressure, volumetric flow rate, velocity, momentum flux, fluid density, and torque, power, and speed of the pump. Five flow measuring devices were used in the broken loop cold leg for measuring the broken loop break flow rate. 


\section{OVERALL THERMAL-HYDRAULIC BEHAVIOR DURING BLOWDOWN}

The results of the data analysis are presented in this section. Analysis related to phenomena which most strongly influence the overall thermal-hydraulic behavior of the system are discussed. Included within the discussion is a description of the general sequence of events occurring within the system as a result of the slow depressurization environment. This section also treats specific thermal-hydraulic phenomena occurring at the break, within the intact loop pump suction leg, and within the core region. Also included is a discussion of the hydraulic phenomena occurring within the vessel following initiation of ECC relative to the ECC effectiveness for the small break test. The influence of the steam generator and piping heat transfer on fluid behavior during Test S-02-6 is mentioned within this section, but not discussed. A detailed discussion of these topics is included within the appendixes.

In order to put the small break (6\%) test in proper perspective with respect to severity of loss-of-coolant accident experiments, the results of Test S-02-6 have been compared in selected cases with results of Test S-02-4[9] which is a $200 \%$ cold leg break test in the blowdown heat transfer test series. Test S-02-4 had essentially the same initial test conditions and ECC system requirements as Test S-02-6, thus providing a basis for comparison of results with those results from the small break test.

The blowdown process for the Semiscale single-ended small break (6\%) was strongly influenced by the break flow rates, the pump behavior, and the pump inlet fluid phenomena caused by the depth of the pump suction leg below the cold leg centerline. The break flow rates were relatively small during the subcooled and saturated portions of Test S-02-6 which resulted in a slow depressurization of the system. The slow depressurization caused the fluid within the vessel and within the intact and broken loop cold legs to remain subcooled for $63 \mathrm{sec}$ after break initiation. The pump, which was coasting down during this extended period of subcooled depressurization, delivered high density fluid to both the core and cold leg break which resulted in a positive flow through the core and relatively good core cooling. The pump coasted down to a stop before saturated flow occurred at the pump inlet. Once the pump stopped, a subcooled liquid plug formed in the pump suction leg. This plug remained until the core liquid level dropped below the lower elevation of the pump suction leg at which time the water plug was blown out. The core partially uncovered during this phase of the test, although a sufficient amount of fluid remained in the core to maintain the rods at temperatures well below the initial temperature values. The accumulator ECC injection was initiated at 600 psig and sufficient water was delivered to fill the core and keep it covered for the remainder of the test.

\section{HYDRAULIC PHENOMENA OCCURRING AT THE BREAK}

The hydraulic phenomena, occurring at the simulated break, control the system depressurization rate and directly influencc much of the hydraulic behavior occurring throughout the system, specifically within the core region. The small break area (6\%) 
employed in Test S-02-6 caused the initial break flow rate to be relatively low in comparison with results of other tests (200\%,breaks) in the blowdown heat transfer series. Figure 8 compares the break flow rate for the small break with that for a $200 \%$ break test. The low

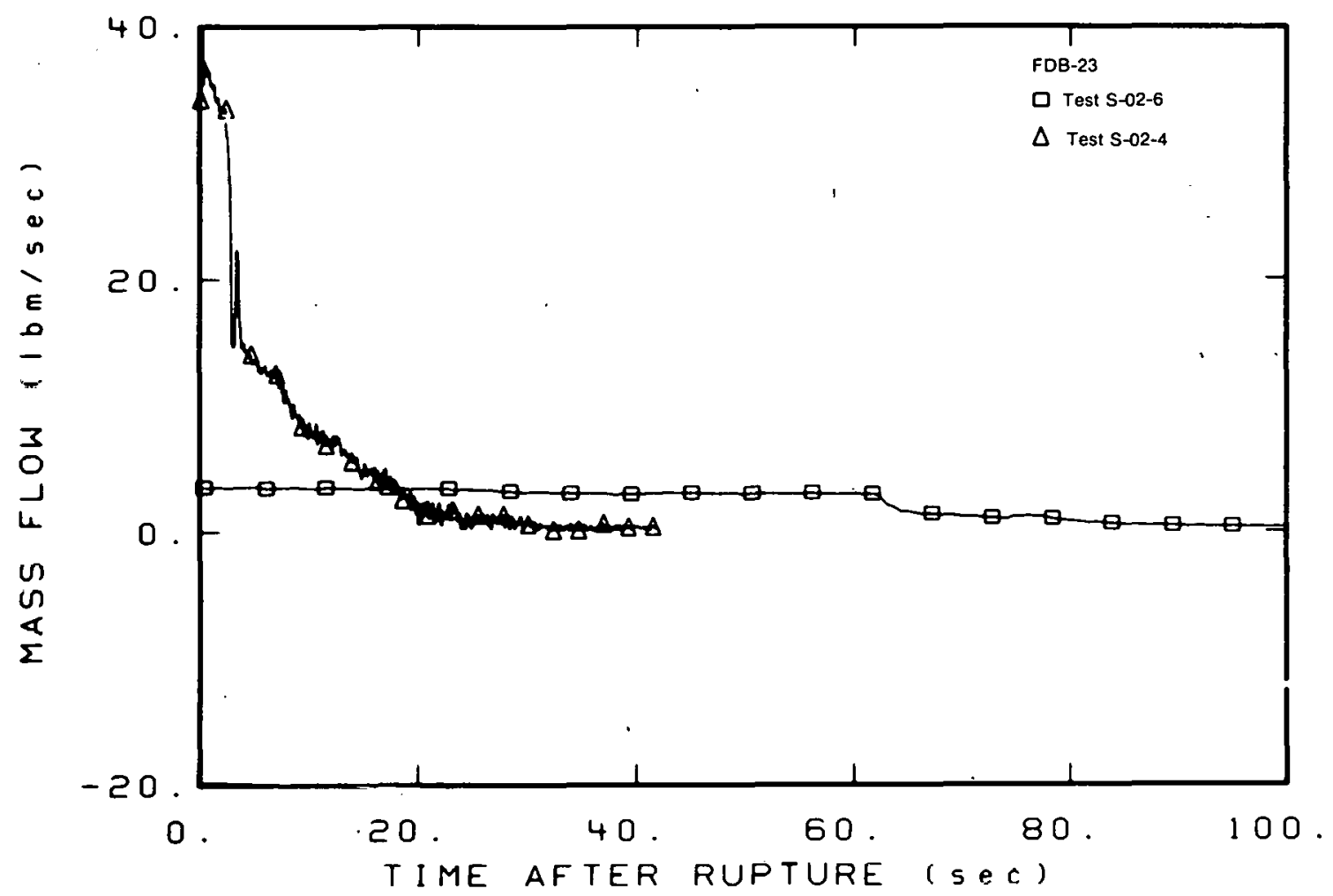

Fig. 8 Comparison of mass flow rates for small break Test S-02-6 and $200 \%$ break Test S-02-4.

$(2.5 \mathrm{lbm} / \mathrm{sec})$, almost constant, break flow rate fur Test S-02.6 results in a much slower depressurization of the system as shown in Figure 9 which caused the subcooled period of flow to be longer ( $63 \mathrm{sec}$ compared with about $3 \mathrm{sec}$ for a $200 \%$ break test). This longer subcooled period of break flow combined with the small break flow rates significantly affected the hydraulic response of the rest of the system.

The fluid hydraulics occurring within the Semiscale intact loop during the first $40 \mathrm{sec}$ of the small break test evidenced that sufficient subcooled fluid had becn supplied to meet the demand of the break. When the intact loop pump coasted down to the point where the flow in the intact loop cold leg could not supply the total demañd of the break, the flow direction in the core reversed to make up the difference betwcen whul was demanded nt the break and what was being supplied from the intact loop. The fact that the break was being supplied by fluid from both the in tact loop and core regions is illustrated in Figure 10 which indicates that the flow rates in the intact loop cold leg and within the core are essentially the same value as that in the broken loop immediately prior to $10 \mathrm{sec}$, but become lower than the break flow rate (an amount equivalent to that coming from the core) subsequent to $40 \mathrm{sec}$. The size of the break, resulting in the slow depressurization rate, affected the time at which the transition between subcooled and saturated fluid occurred at the break. Figure 11 shows the fluid temperature at the break versus the saturation temperature corresponding to 


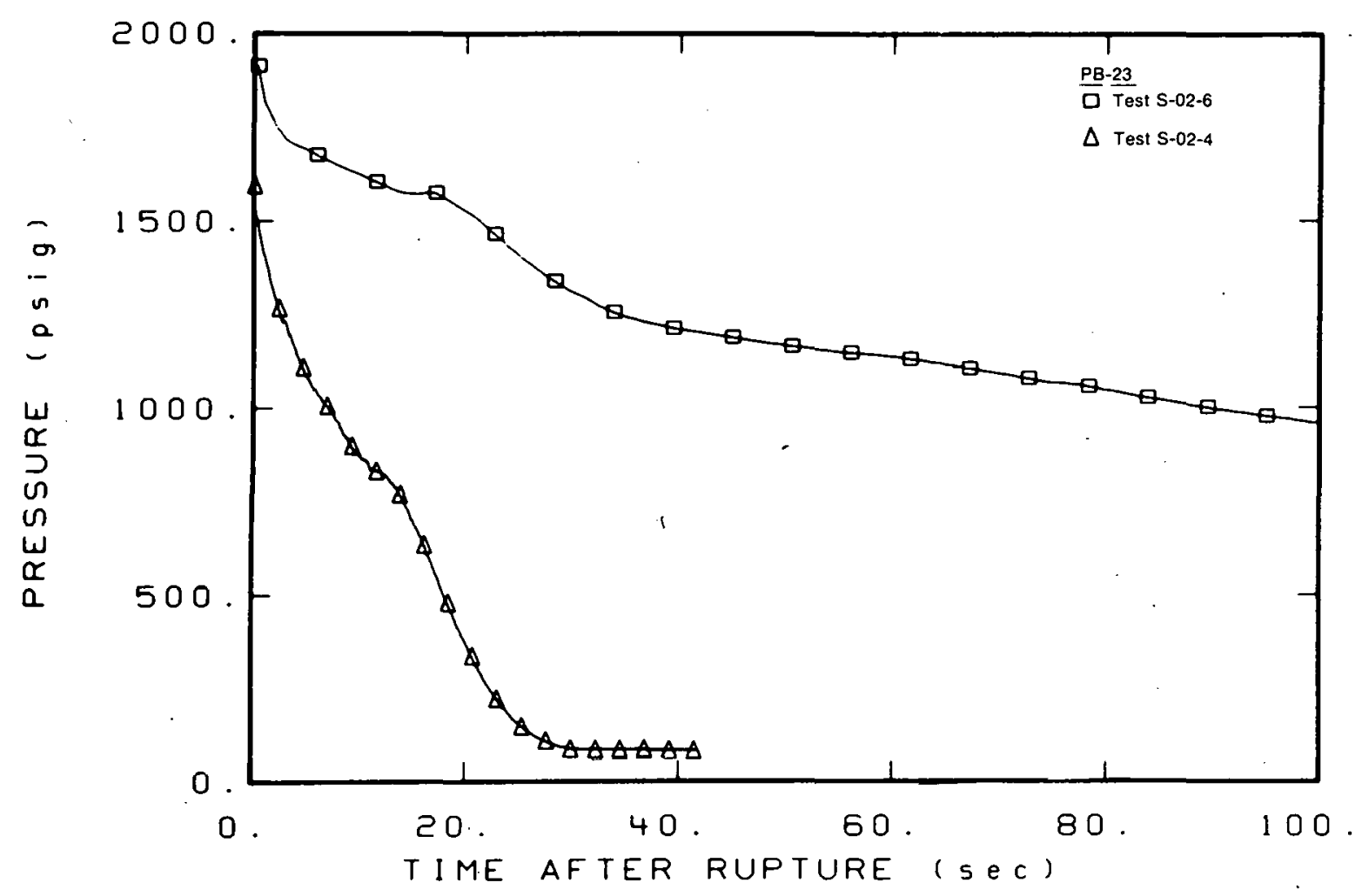

Fig. 9 Comparison of pressures at the break for small break Test S-02-6 and 200\% break Test S-02-4.

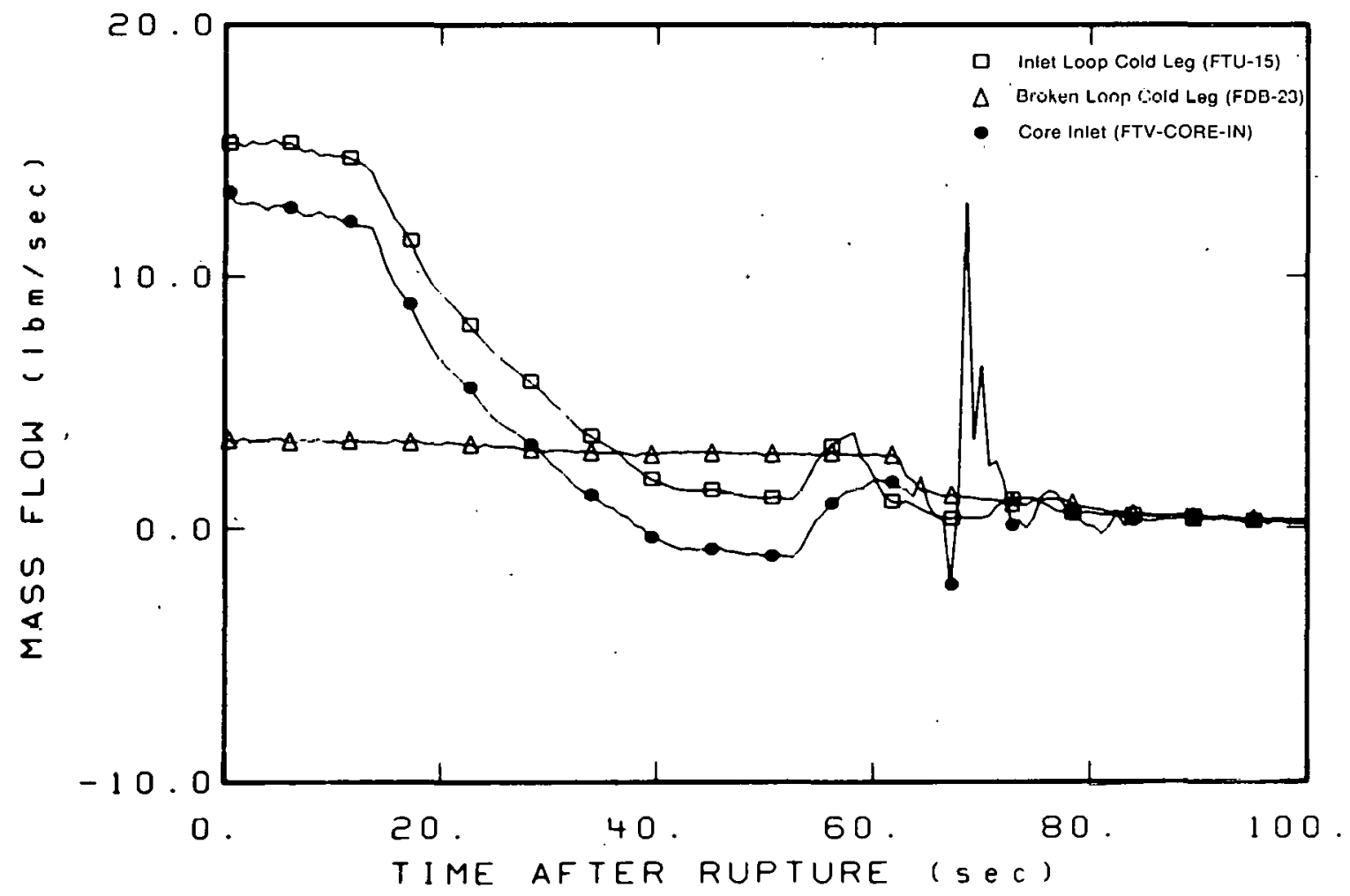

Fig 10 Mage flow rates al the cure Inlet ảnd at intact and broken loop cold legs - Teșt S-02-6. 


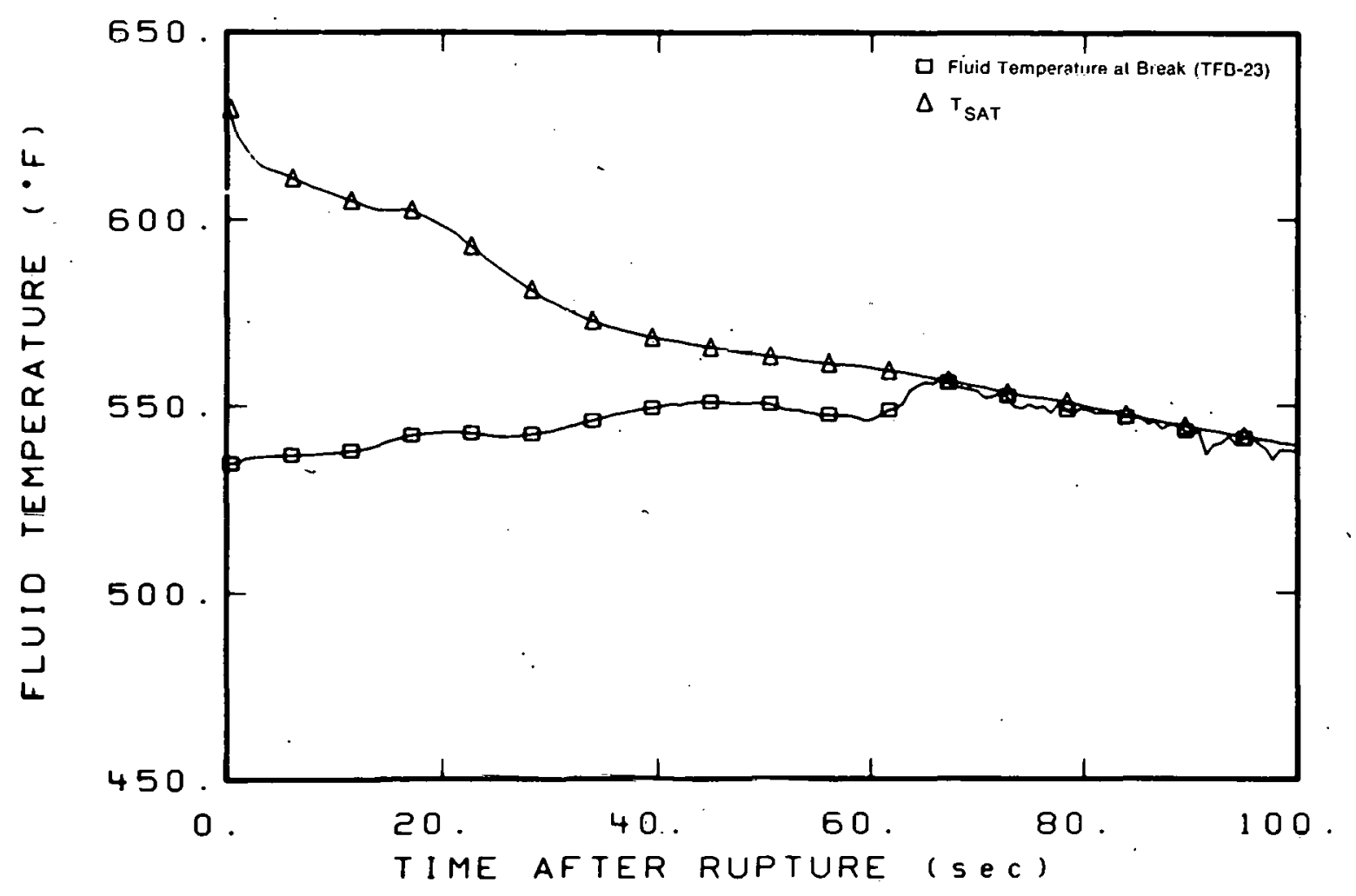

Fig. 11 Fluid temperatures at the break versus saturation temperature - Test S-02-6.

the measured pressure. Oncc saturation conditions existed at the bieak, the timo period botween 63 ser. and the time at whioh ECC fluid entered the system $(290 \mathrm{sec})$ was essentially uneveritful. That is, all significant dynamic effects of the blowluwn were ovor by $63 \mathrm{sec}$, and as a result of sustained positive tlow through the corc, the core thermal raspnnse was such that the temperature of all of the rods was below $600^{\circ} \mathrm{F}$ by this time.

\section{FLUID BEHAVIOR GOVERNED BY PUMP SIUCTION PIIENOMENA}

Making the pump suction leg longer to better represent PWR geometry for Test S-02-6 resulted in on intact loop and core fluid behavior within the Semiscale system which was typical of that expected in a PWR under small break conditions. The additional length of the pump suction leg resulted in the proper establishment of a water seal which formed in the pump suction pipe during and following the pump coastdown. As illustrated in Figure 12, water in the pump suction formed a seal which blocked the flow of steam between the intact loop hot and cold legs during the blowdown periud. With cssentially no intact loop flow, the collapsed water level in the core decreased at the same rate as the water level in the pump suction leg. As illustrated, the level in the pump suction leg could decrease well below the elevation of the cold leg piping which remained full of water. Once the water 


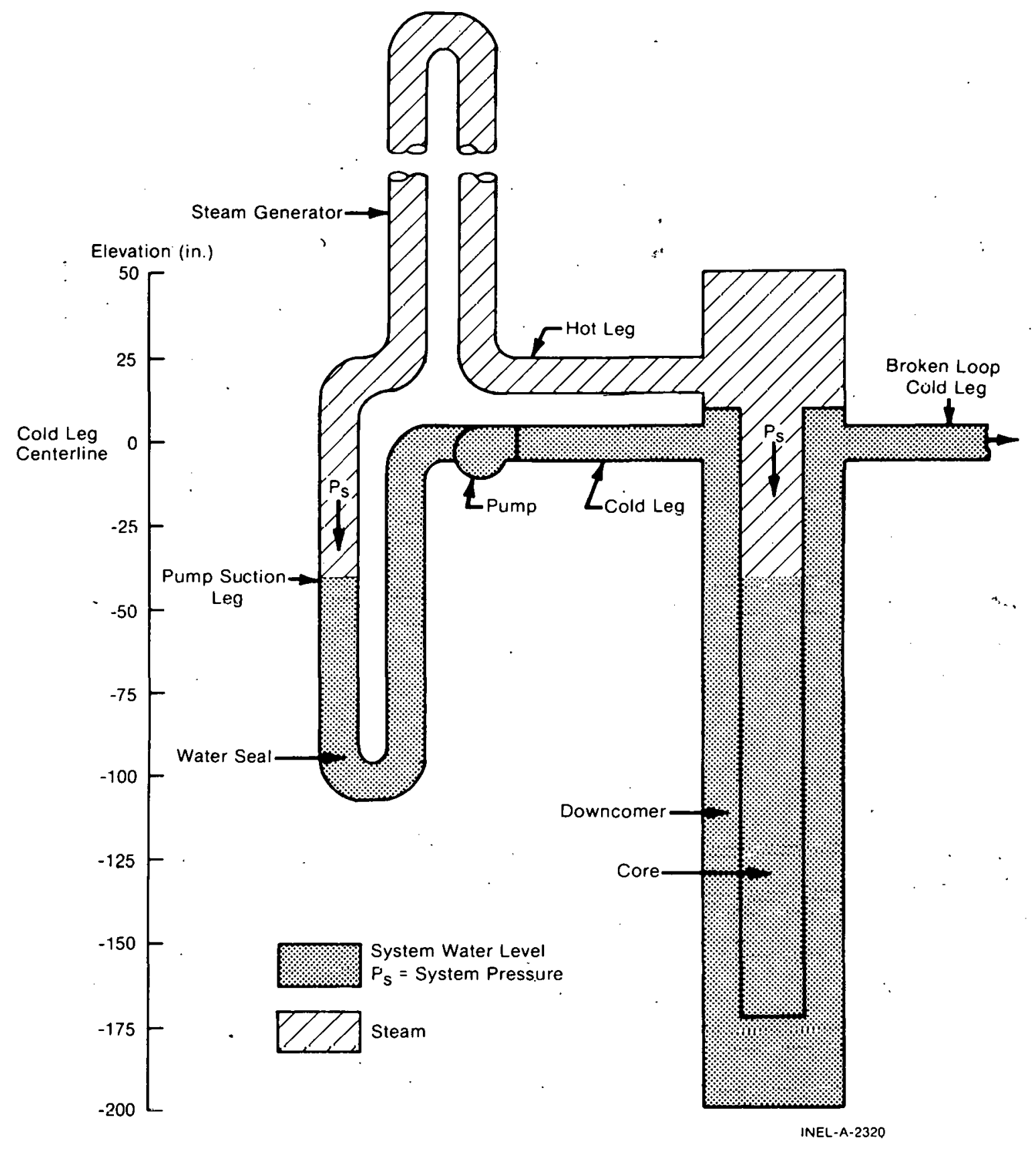

Fig. 12 Illustration of pump suction seal - Test S-02-6.

level reached the hottom of the pump suction pipe, the water seal would be expected to blow out and the pressure would equilibrate which would cause the collapsed water levels in the core and downcomer to equilibrate to the same height.

The effect of a water seal forming at the pump suction was observed during Test S-02-6. This seal in the intact loop was characterized by a high density fluid at the pump inlet, and low density fluid within the hot leg of the intact loop. The density measured at the intact loop hot leg during the first $40 \mathrm{sec}$, shown in Figurc 13, indicated large stcam 


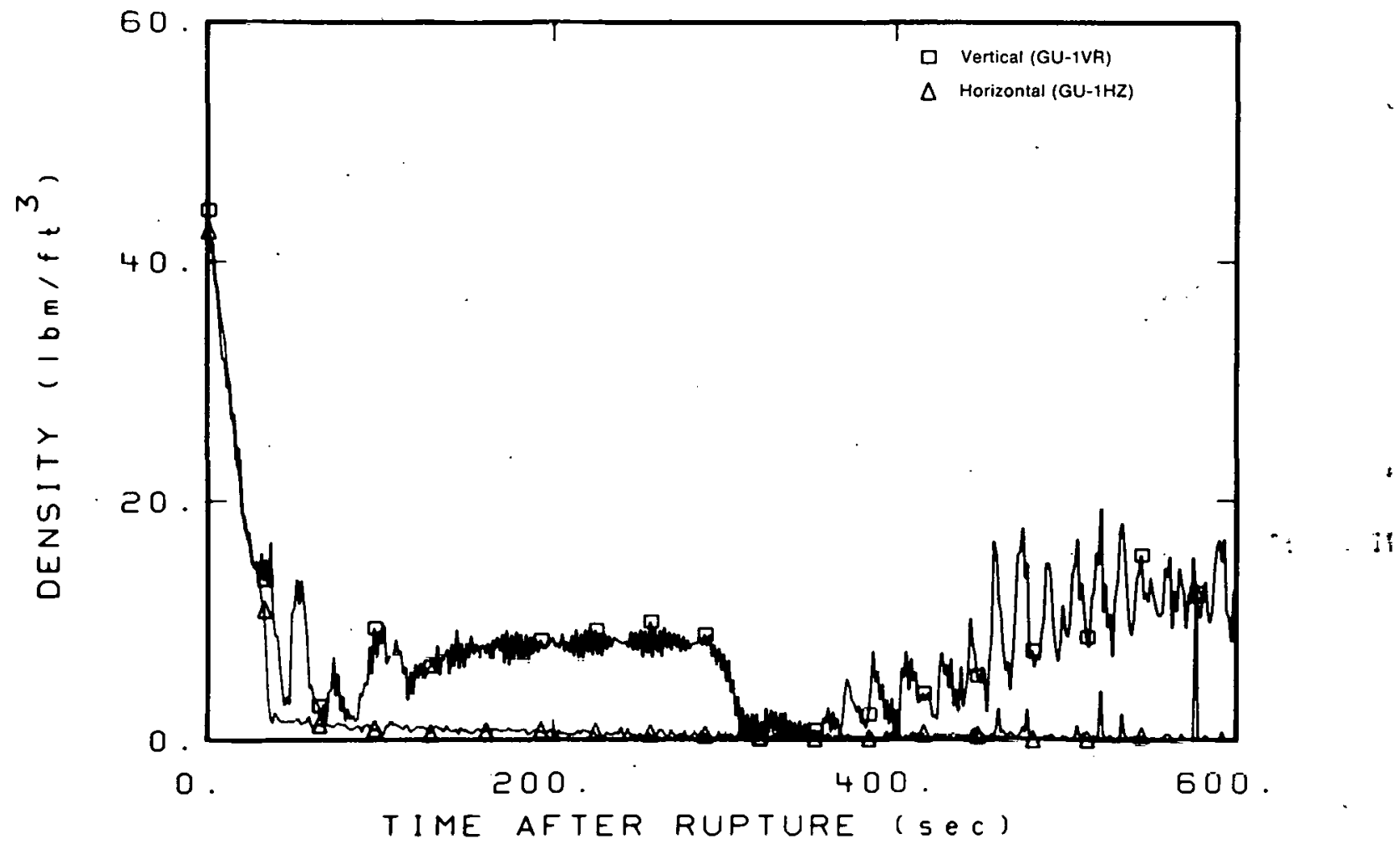

Fig. 13 Fluid densities at the intact loop hot leg - Test S-02-6.

content which was caused by the generation of stean both from liquid flashing in the hot

- leg and from liquid boiling within the heated core. Heat transfer from the intact loop hot leg fluid to the steam generator secondary side, along with the subconled water within the primary piping, was sufficient to condense steam flowing from the hot leg to the cold leg during the first $40 \mathrm{sec}$ of blowdown. The occurrence of this phenomenon is illustrated by fluid temperatures on both sides of the steam generator (TSU-6 and TFU-8). These temperatures are compared with the saturation temperature in Figure 14. Just after $40 \mathrm{sec}$, a flow stagnation occurred just upstream of the stopped pump.

As the pump stopped (about $40 \mathrm{sec}$ after rupture) the flow reversed direction at the core barrel inlet as shown in Figure 15, and the core collapsed liquid level (calculated from a differential pressure measurement across the core) decreased well below the level of the liquid in the downcumei and intnct loop cold leg as indicated in Figure 16. Figures 17 through 20 illustrate what occurred to the pump seal between 40 and $100 \mathrm{sec}$ after rupture. The system water levels represented in the figures were obtained from differential pressure measurements and are only representative of the true water levels. The differences in level that cxist (where the same levels would be expected) are due to pressure drops between the two points and to the method of obtaining the collapsed liquid levels. Prior to $40 \mathrm{sec}$ the depressurization of the system was sufficiently slow that stratification occurred in the upper plenum, and the upper plenum drained much like a reservoir would that has a leak somewhere lower in its system. A calculation of the upper plenum level using an integration of the break mass flow provided a very good comparison with the level shown in Figure 17. 


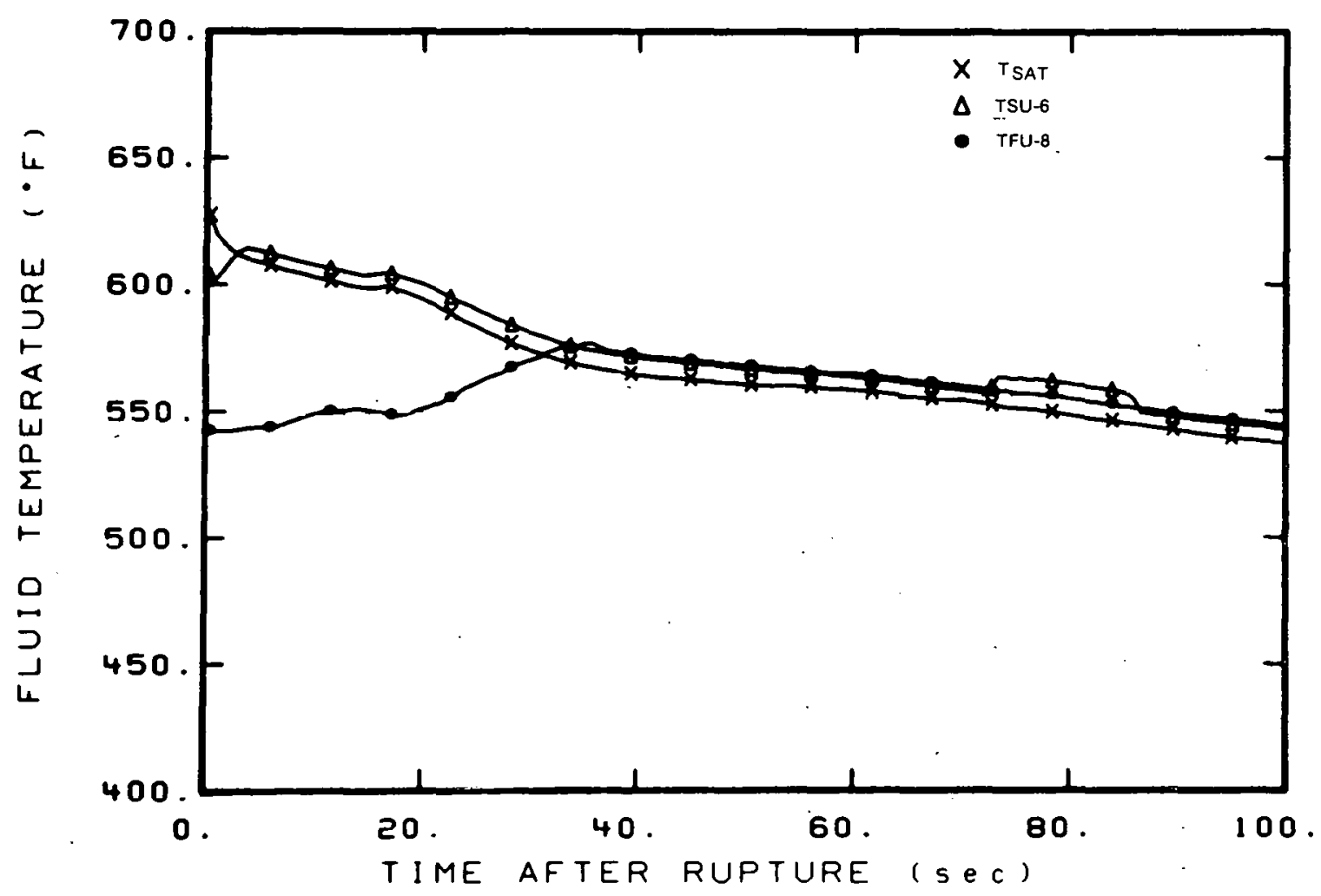

Fig. 14 Fluid temperatures on each side of the steam generator - Test S-02-6.

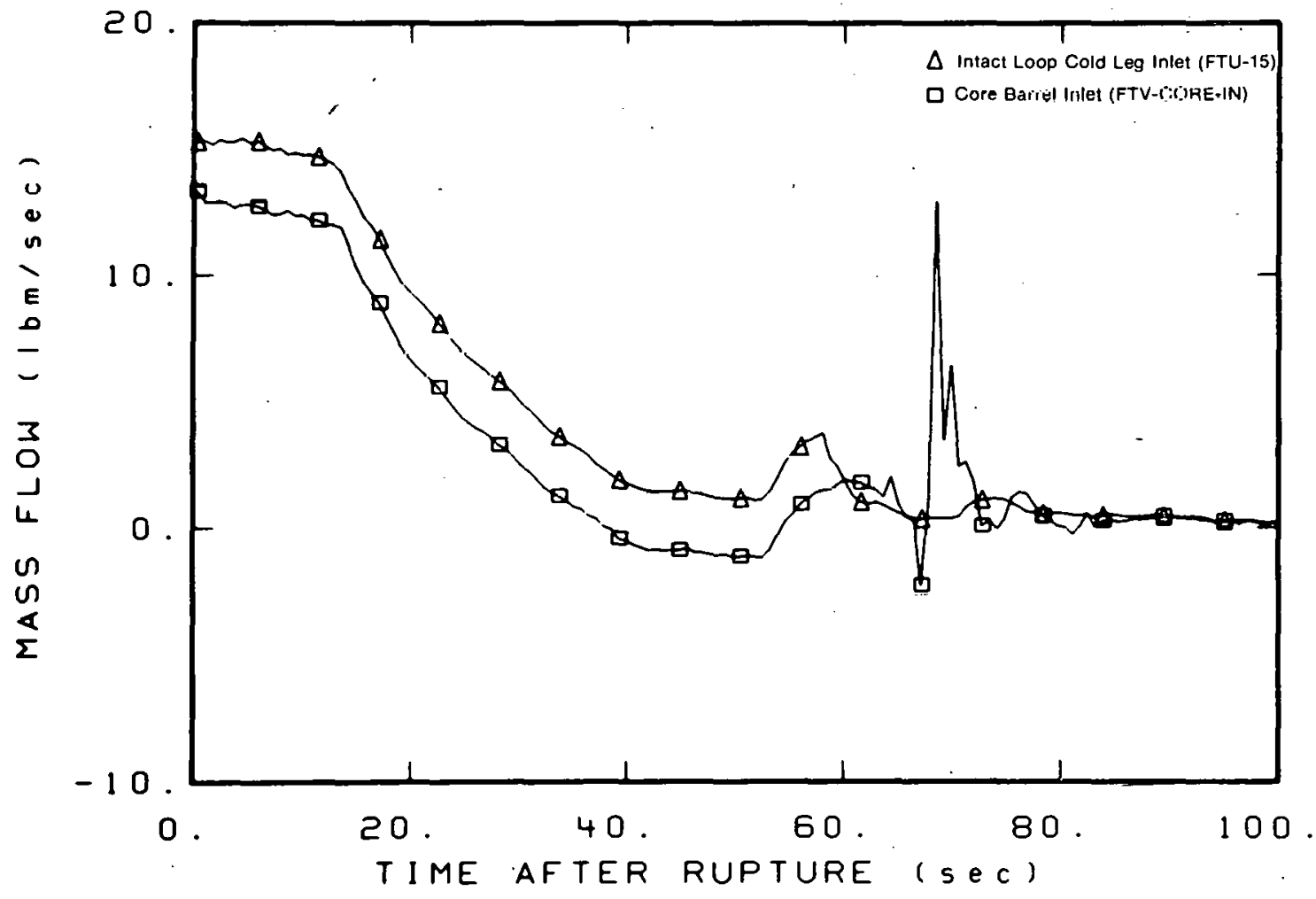

Fig. 13 Mass now ratès at the core harrel inlet and intact loop cold leg - Test S-02-6. 
As illustrated in Figure 17, at $40 \mathrm{sec}$ after rupture the pump suction leg had started to drain below the cold leg centerline even though the density measurement indicated the cold leg was full. By $50 \mathrm{sec}$ after rupture (Figure 18) the pump suction leg collapsed liquid level was 65 in. below the cold leg centerline, and the core liquid level was well below the top of the heated core. A stagnation condition existed at this time in the pump suction leg just

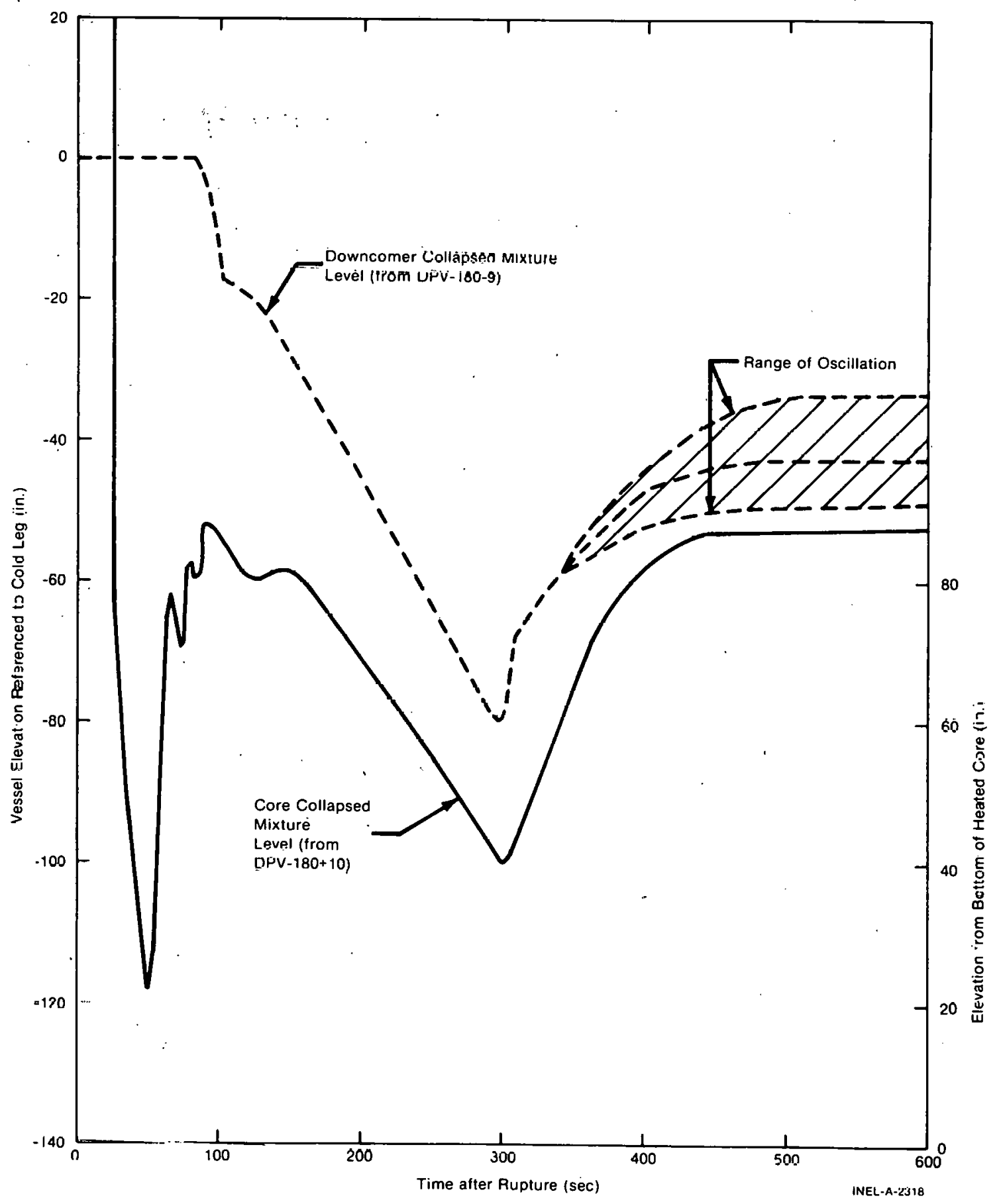

Fig. 16 Collapsed liquid levels in the downcomer and core from differential pressure measurements - Test S-02-6. 
upstream of the pump, caused by the pump having stopped. However, positive flow through the pump was reestablished so that just after $60 \mathrm{sec}$ following rupture the pump seal blew out and a direct hydraulic coupling existed between the intact loop and the core. Figure 19 illustrates the fluid conditions in the pump suction leg just prior to the seal blowing out. By $100 \mathrm{sec}$ after rupture the system was hydraulically balanced as illustrated in Figure 20.

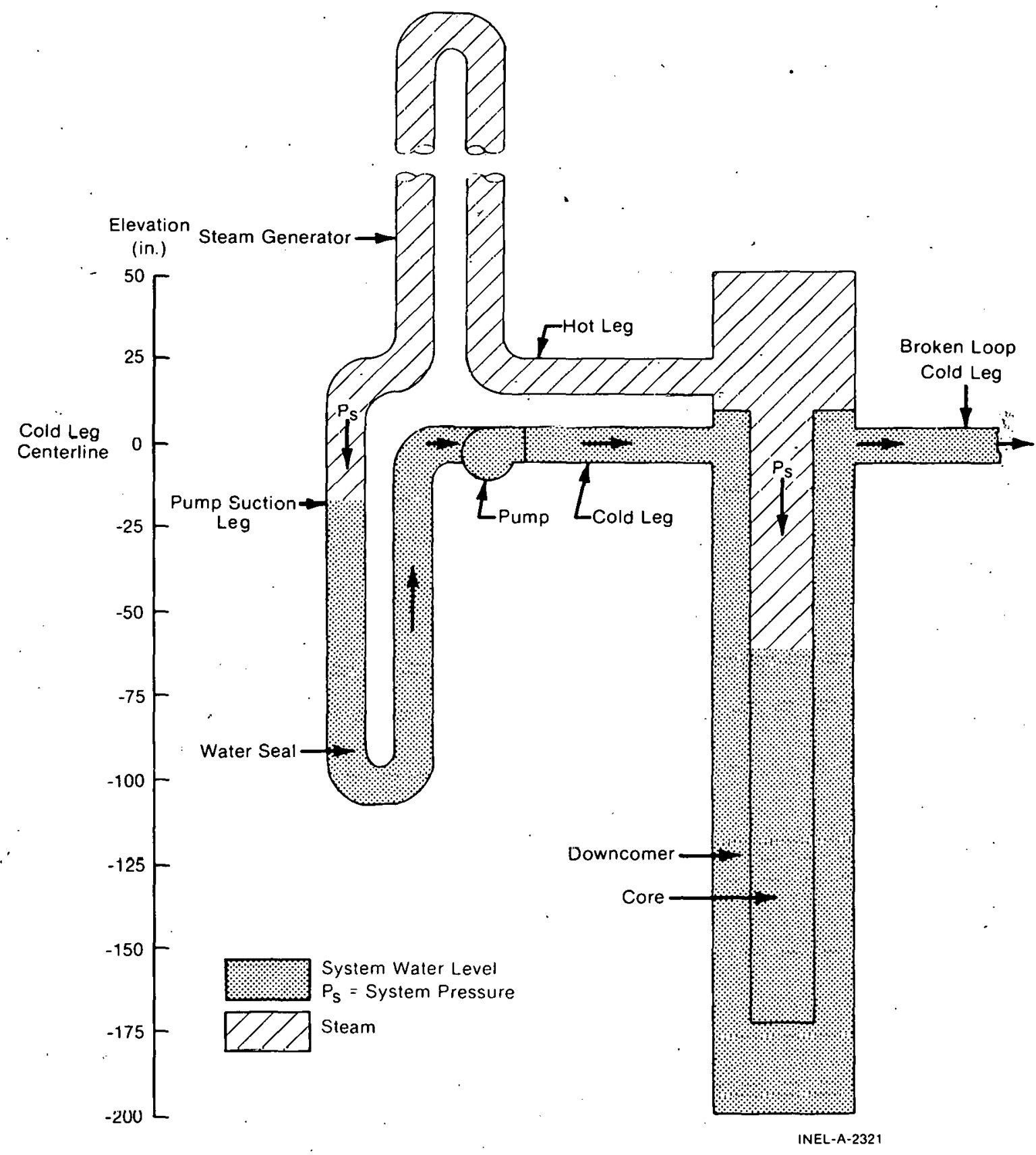

Fig. 17 Illustration of systcm hydraulic condition at $40 \mathrm{sec}-$ Test S-02-6. 


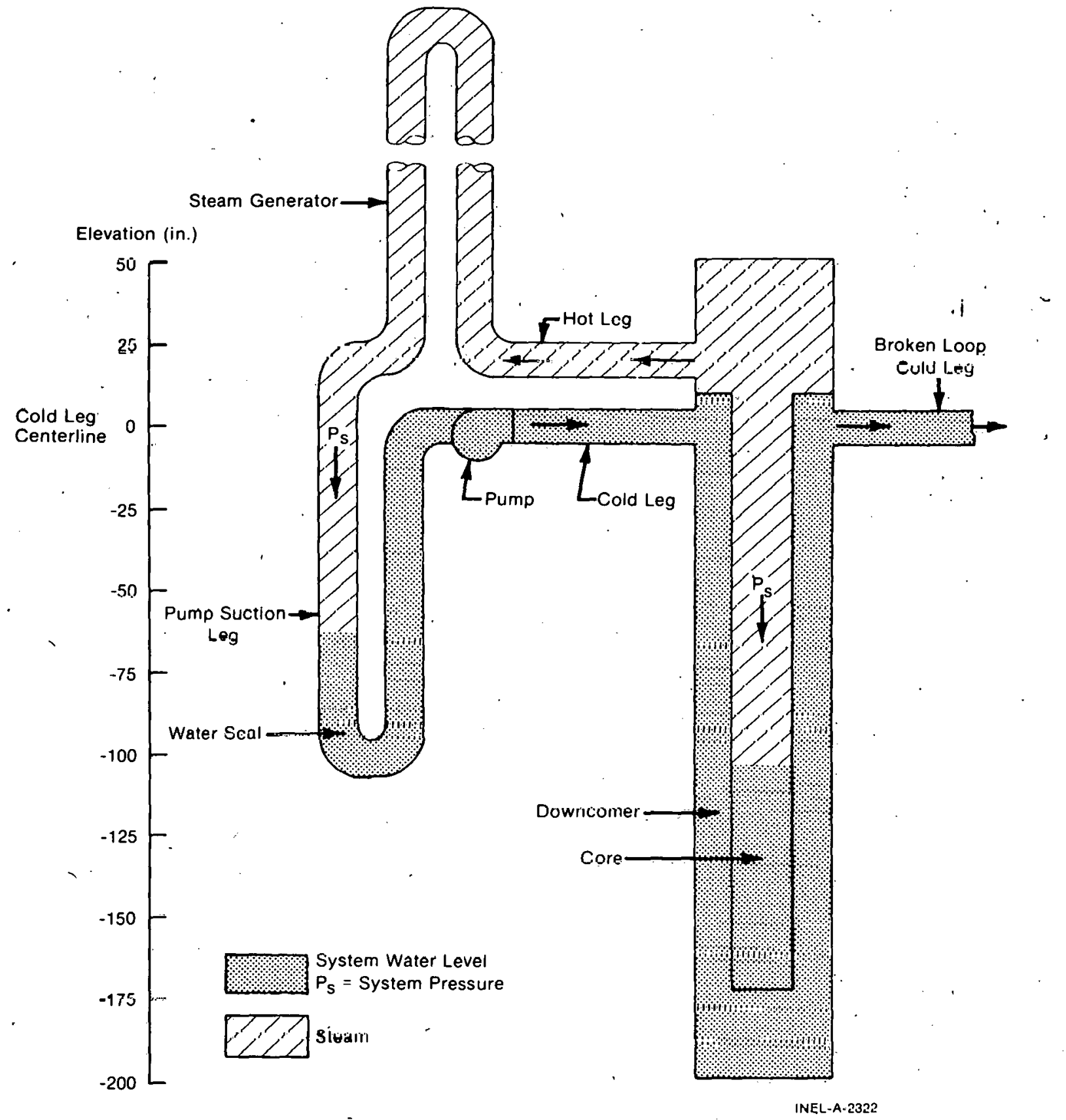

Fig. 18 Illustration of system hydraulic condition at $50 \mathrm{sec}-$ Test S-02-6. 


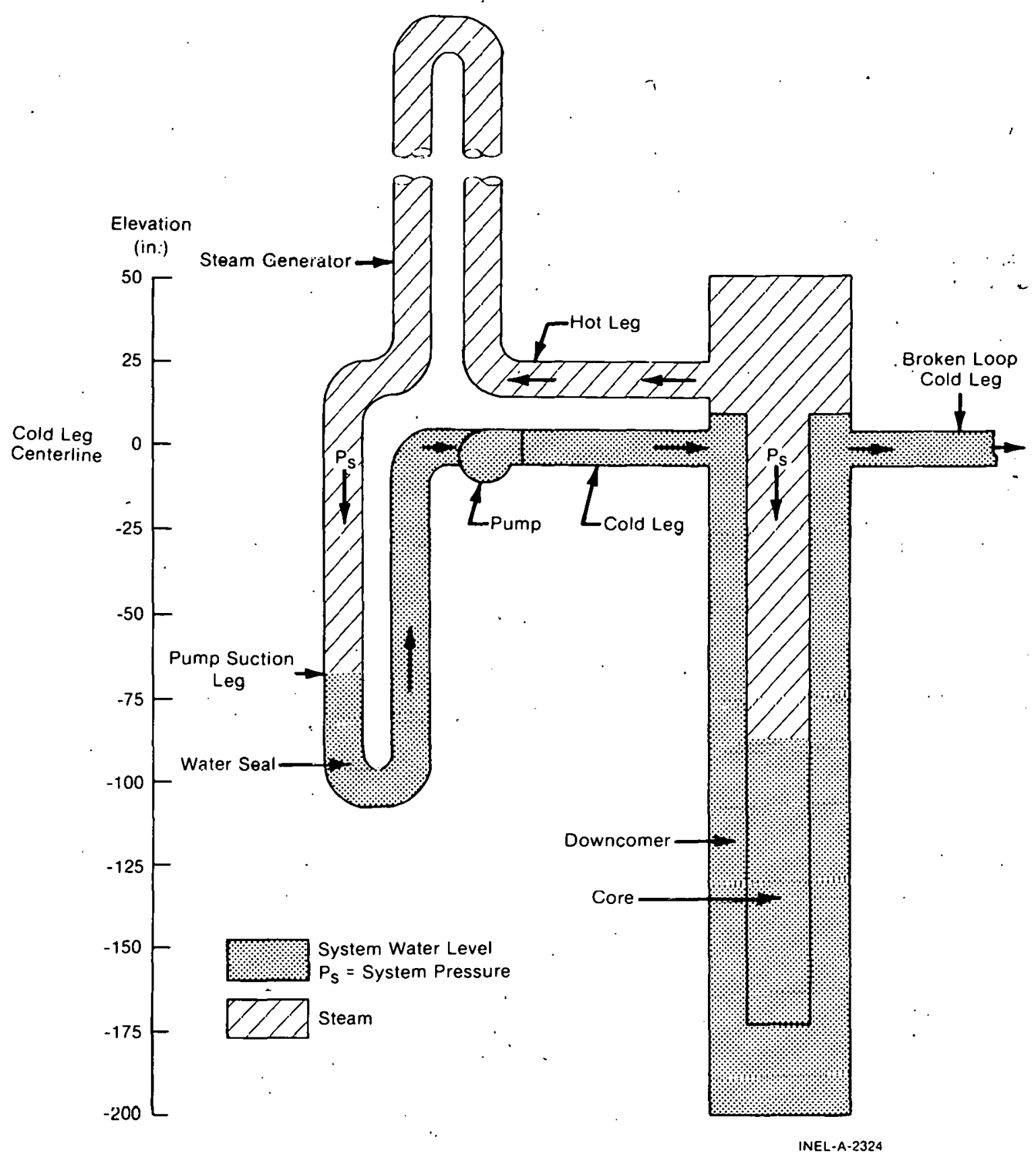

Fig. 19 Illustration of system hydraulic condition at $60 \mathrm{sec}-$ Test S-02-6. 


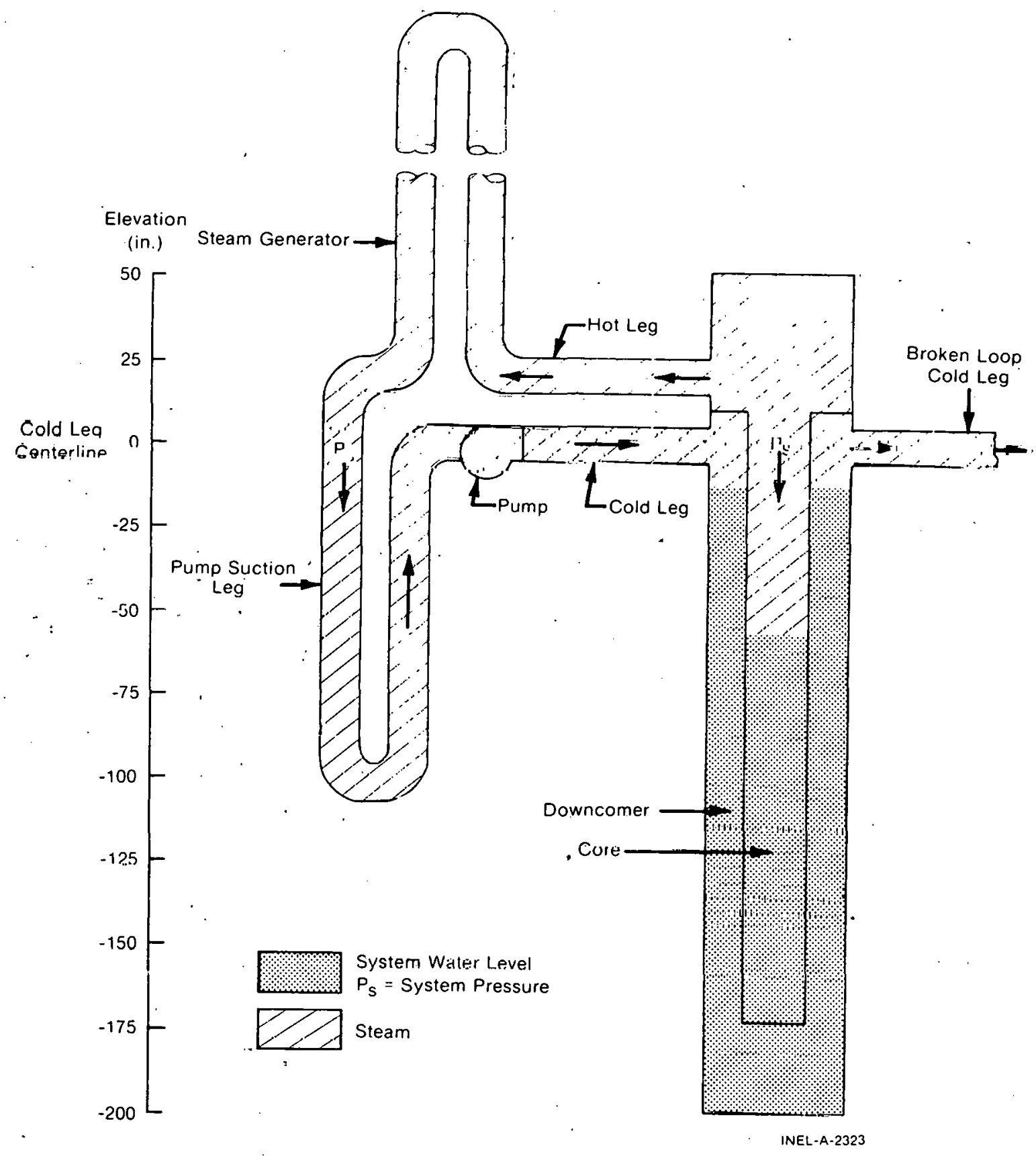

Fig. 20 Illustration of sysiem liydiaulie condition at 100 ses. - Test S-02-6.

\section{CORE THERMAL-HYDRAULIC PHENOMENA}

The: small break size combined with the single broken loop configuration caused a core hydraulic' response that was different than that of previous Mod-1 tests. The core flow remained in the positive direction for the first 38.sec of blowdown because the intact loop .. cold leg flow was sufficient to supply the break demand for flow. The positive core flow was 
enhanced by the fact that the pump head did not completely degrade until $40 \mathrm{sec}$ after rupture. Once the pump stopped, the intact loop cold leg flow could not completely supply the demand at the break, and a reversed core flow (up the downcomer) resulted, thus complementing the intact loop flow to the break as shown in Figure 15.

The fluid behavior within the core during the early blowdown period provided excellent cooling throughout the blowdown period as illustrated in Figure 21. The only exception to a continual cooling of the heater rods during this test occurred after $40 \mathrm{sec}$.

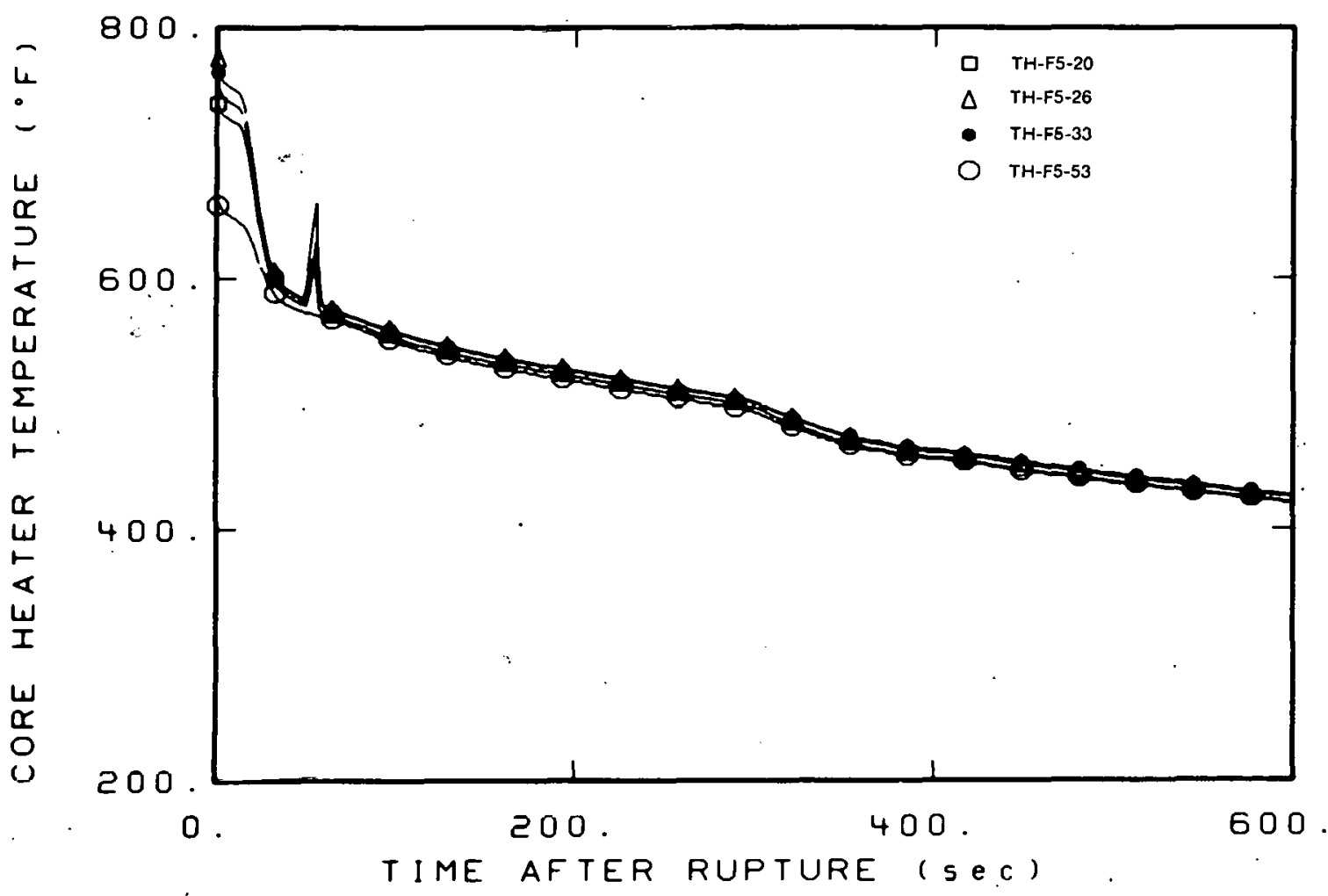

Fig. 21 Core temperature response (Rod F6) - Test S-02-6.

About $50 \mathrm{sec}$ after rupture the corc collapsed liquid level decreased below the top of the heated core. Al this time a sharp, but minor, increase in some rod temperatures was observed. For the one heater rod shown, the bottom of the rod experienced a temperature increase typical of a boiling crisis whereas the top of the rod did not. This type of heater rod response is not indicative of a decreasing liquid level, but suggests that an axial quality gradient existed in the core. At the top of the core where the power generation rate was low, the quality was sufficiently low to illaintain good cooling. In the center of the core where the power was high the quality of the mixture led to the observed departure from nucleate boiling (DNB).

A radial variation occurred in the temperature response of the rods which experienced a boiling crisis. As shown in Figure 22, only rods opposite the intact loop hot leg experienced a rapid temperature rise at $50 \mathrm{sec}$. Since incore density and flow measurements were not possible, the cause of this asymmctric cure behavior can only be hypothesized. After the pump stopped, coolant in the intact loop hot leg was observed to flow back into 


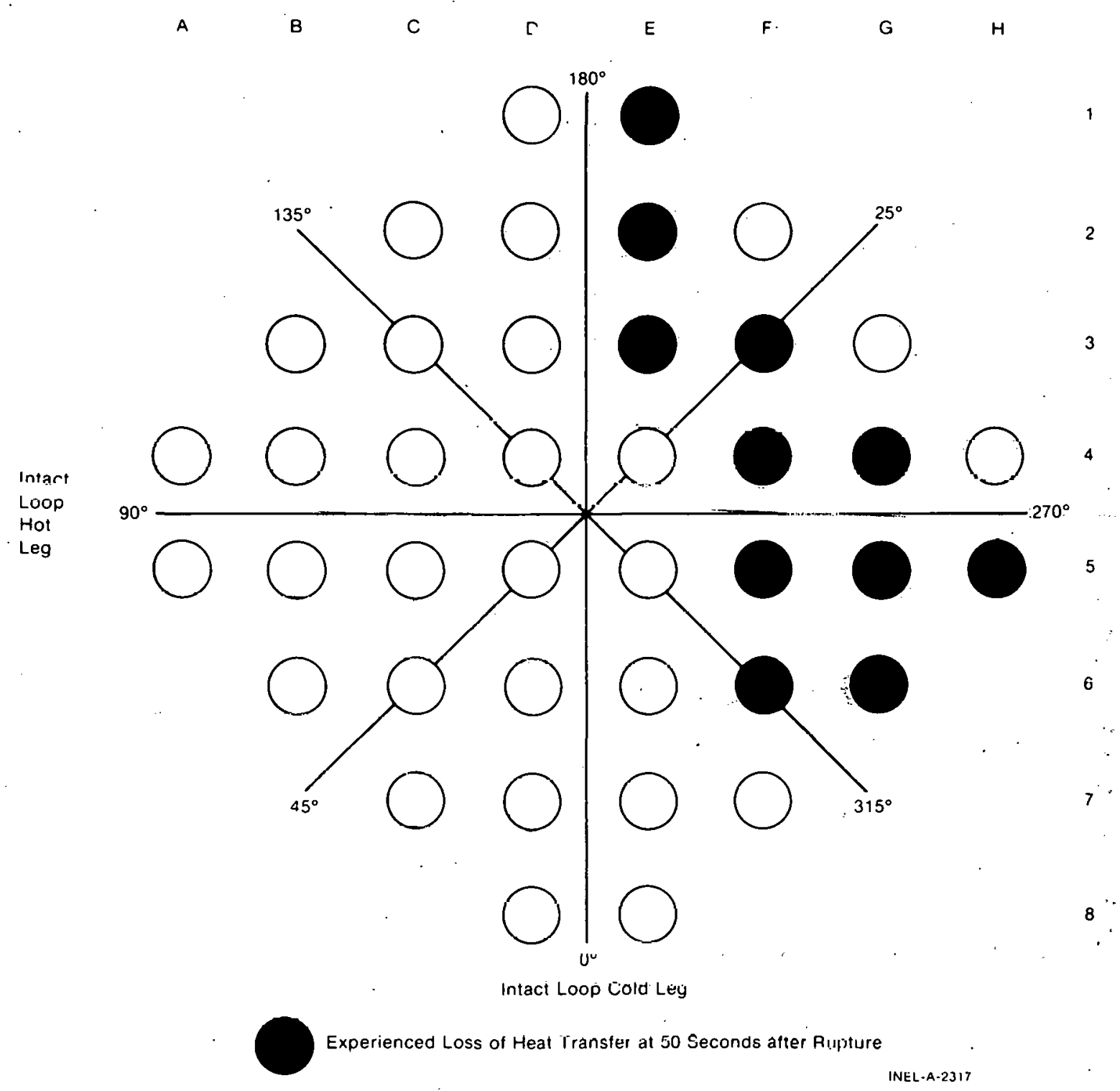

Fig. 22 Semiscale Mod-1 heated core configuration showing radial locations where rods experlenct different tomporature response.

core. Without strong dynamic mixing, the coolant entering the upper plenum from the hol leg had a preferred path down one side of the core barrel while lighter steam flowed up the other side. This flow pattern would be expected for free convertion. Rods on the intact loop hot leg side of the cole would be subjected to the influx of a lower quality mixture than those on the opposite side of the core. As expected, only those rods opposite the intact loop hot leg experienced a builing crisis whereas rods on the other side of the core did not.

At about $60 \mathrm{sec}$ after rupture, water in the cold leg partially passed out the break and also dropped into the downcomer as seen from a decrease in both broken and intact loop densities in Figure 23. With the loss of mass in the broken loop cold leg, the break uncovered and the break flow changed from subcooled to saturated flow. Fluid in the downcomer flowed into the core causing the downcomer mixture level to drop and the core 


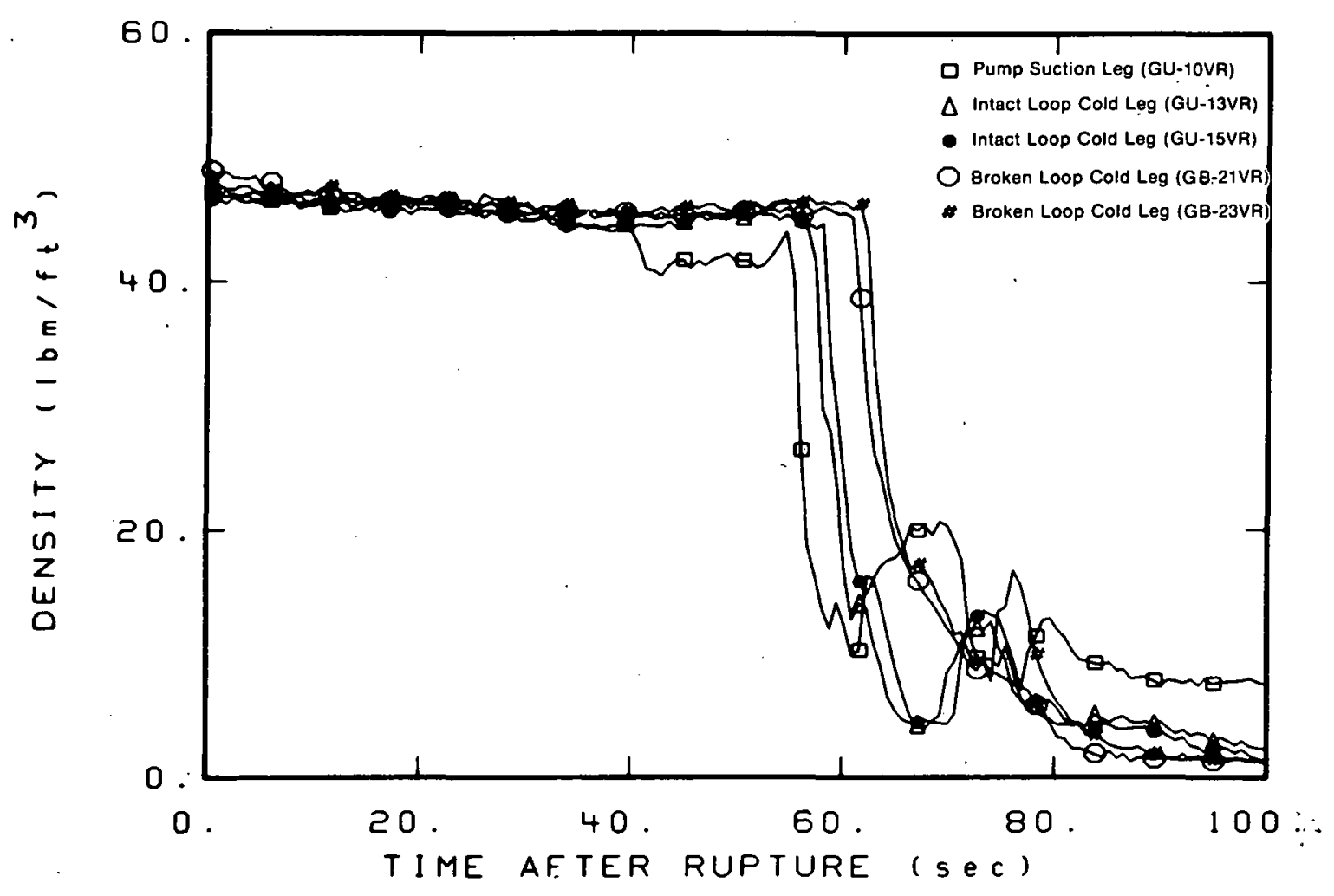

Fig. 23 Fluid density in system piping - Test S-02-6.

collapsed mixture level to rise (as interpreted from measured differential pressure data in Figure 16). The resulting upward coolant flow through the core (Figure 15) caused those heater rods that experienced a boiling crisis to rewet.

From the time saturated conditions existed at the break until the accumulators injected water, the core collapsed mixture lcvel decreased, but the core was maintained in a continual cooling condition. When the accumulators injected water, the core collapsed mixture level rose well above the heated region of the cone.

Core temperatures greater than the initial operating temperatures did not occur during Test S-02-6, and the emergency core coolant was sufficient to cool the core and keep it covered during the latter portion of the test. The conclusion is that in the Semiscale Mod-1 system the small break did not result in a rod thermal behavior as severe as observed in the large break tests and thus the small break results in a less sevcre loss-of-coolant experiment.

\section{HYDRAULIC PHENOMENA OCCURRING IN THE VESSEL \\ FOLLOWING INITIATION OF ECC}

The effectiveness of ECC injection systems during hlowdown was detcrmined un the basis of the core thermal behavior. From the time the pump suction seal blew out $(60 \mathrm{sec})$ 
until the accumulators started water injection ( $300 \mathrm{sec}$ at a system pressure of 600 psia) the core contained sufficient coolant to remain cool as shown by the heater rod temperature response. When the accumulators began injecting water, some condensation of steam was observed downstream from the injection point as illustrated in Figure 24 by the decrease in fluid temperature below the saturation temperature. The lower fluid temperature increased the amount of energy being removed from the piping walls, but not appreciably, as discussed in Appendix B. The condensation of steam caused by the ECC injection resulted in a small decrease in system pressure as shown in Figure 25. The local decrease in pressure that resulted from steam condensation and the increased steam generation that resulted from a rise in the core mixture level increased the volumetric flow within the intact loop as shown in Figures 26 and 27. The injection rate was low ( 2 to $3 \mathrm{gpm}$ ) but even this low flow rate raised the collapsed liquid levels in the downcomer and cnre as shown in Figure 16. These processes resulted in excellent core cooling which illustrates the effectiveness of the ECC systems under small break conditions.

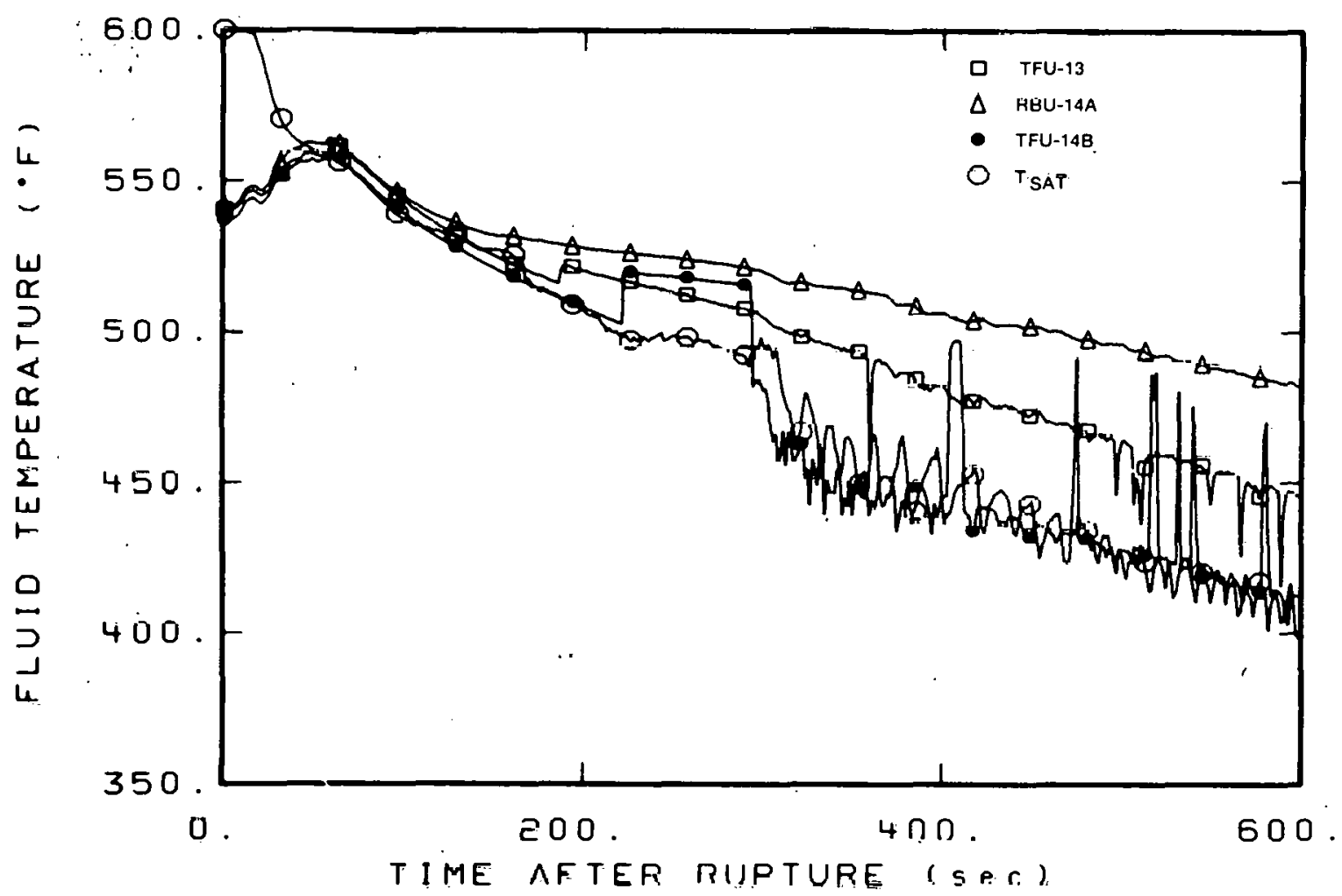

Fig. 24 Intact loop cold leg fluid temperatures - Test S-02-6. 


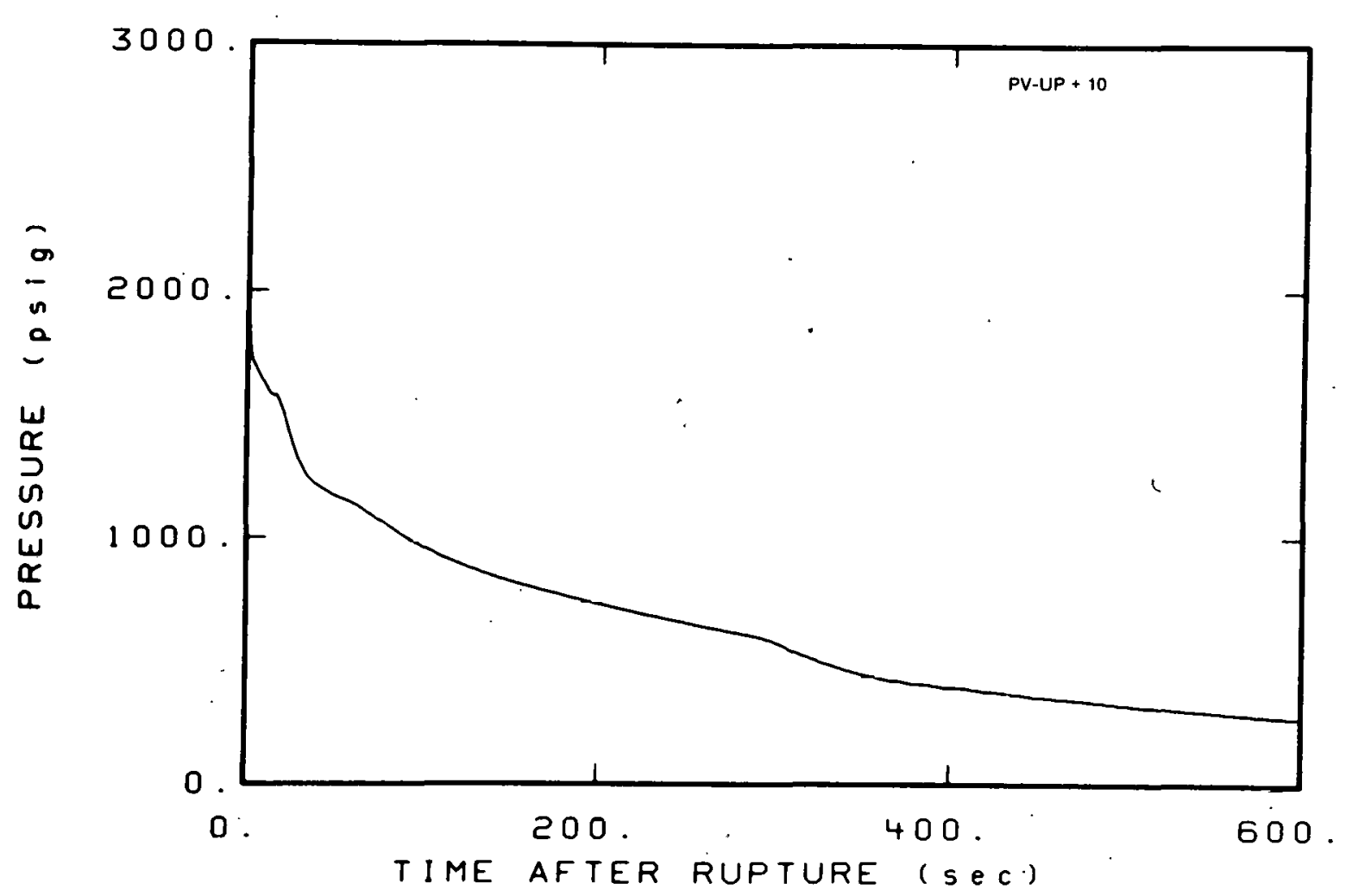

Fig. 25 Upper plenum system pressure - Test $\$-02-6$.

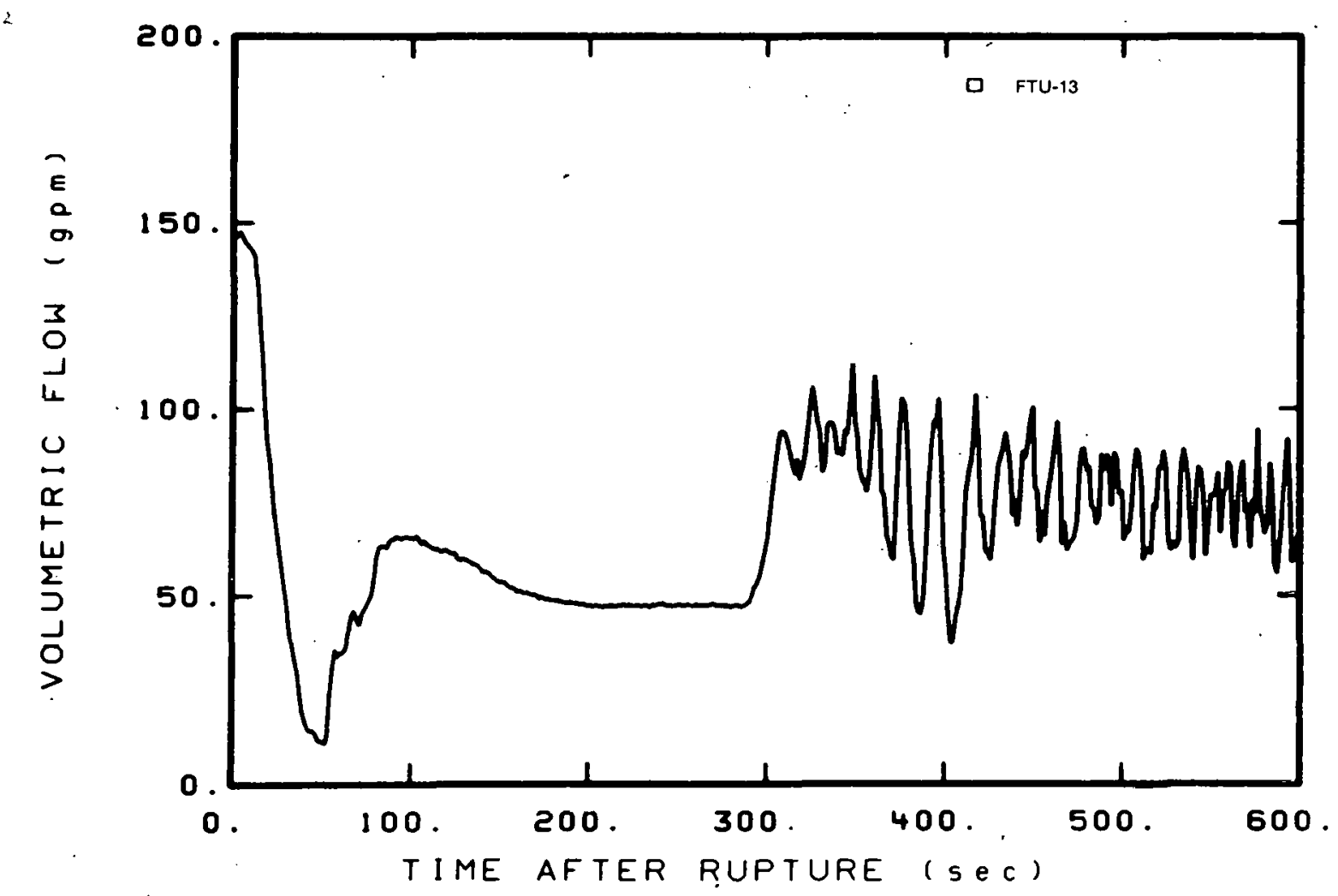

1'ig. 26 Intact loop cold leg volumetric flow rate - Test S-02-6. 


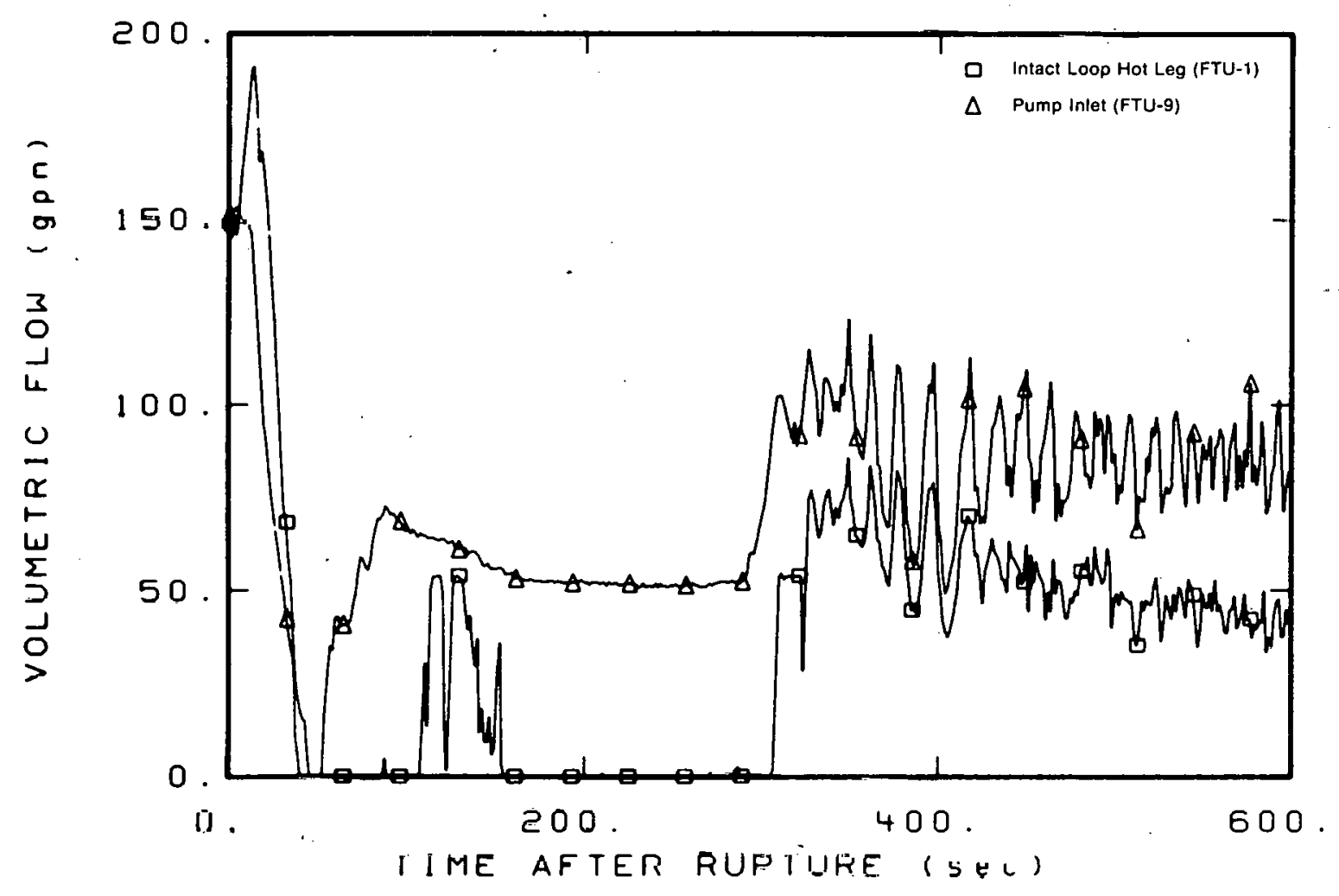

Fig. 27 Intact loop hot leg and pump inlet volumetric flow rates - Test S-02-6. 


\section{CONCLUSIONS}

Test S-02-6 was performed to supply data for NRC Standard Problem Six. The analyses and investigations of these data were performed to validate the data for such use. The following is a summary of the conclusions reached from the analyses of the data obtained during the Semiscale Mod-1 Test S-02-6.

The simulated single-ended small break $(6 \%)$ of Test S-02-6 resulted in a much longer subcooled blowdown period (63 sec compared with about $3 \mathrm{sec}$ for a $200 \%$ break), and a much slower depressurization (system pressure of 600 occurring at $290 \mathrm{sec}$ instead of $17 \mathrm{sec}$ for a $200 \%$ break) of the system.

The hydraulic process occurring within the Semiscale system during subcooled blowdown ( 0 to $63 \mathrm{sec}$ ) was one of sufficient subcooled fluid being supplied to meet the demand at the break. When, due to pump degradation, the intact loop cold leg could not supply the total demand, the flow direction in the core reversed in order that the difference between what was demanded and that being supplied by the intact loop could be met.

The period of time from the end of subcooled flow $(63 \mathrm{sec})$ to the time of emergency core coolant injection $(290 \mathrm{sec}$ ) was uneventful bccause all significant dynamic events were completed by the time the subcooled blowdown was complete and because the core thermal response was such that the temperature of all of the rods was below $600^{\circ} \mathrm{F}$ at the beginning of saturated blowdown.

A pump suction seal formed during blowdown and the resulting phenomena relating to the pump seal blowout that occurred in the pump suction leg piping were as expected, that is, the seal remained until the core liquid level dropped below the lower elevation of the pump suction leg at which time the seal blew out.

The hydraulic behavior within the core during the blowdown period provided the means for excellent sore cooling throughuul the blowdown period. Although the punp stopped and a pump suction seal occurred, the resulting severity with respect to peak cladding temperature was minor.

Core temperatures above the initial operating temperatures did not occur during Test S-02-6, and the injected emergency core coolant was sufficient to cool the core and keep it covered during the latter portion of the test. The small break did not result in a rod thermal behavior as severe as observed in the large break tests and, therefore, the small break test represents a less scvere lóss-of-coolant experiment. 


\section{REFERENCES}

1. Quarterly Technical Report on Water Reactor Safety Programs Sponsored by the - Nuclear Regulatory Commission's Division of Reactor Safety Research, January - March 1975, ANCR-1254 (September 1975) pp 29-60.

2. T. K. Larson, Core Thermal Response During Semiscale Mod-1 Blowdown Heat Transfer Tests, ANCR-1285 (June 1976).

3. J. M. Cozzuol, Thermal-Hydraulic Analysis of the Semiscale Mod-1 Blowdown Heat Trunsfer Tent .Series. ANCR-1287 (June 1976).

4. D. G. Hall, A Study of Critical Flow Prediction for Seritscale Mud-1 Loss-of-Coolant Accident Experiments, TREE-NUREG-1006 (December 1976).

5. D. M..Snider, Analysis of the Thermal-Hydraulic Behavior Resulting in Early Critical Heat Flux and Elevation of CHF Correlations for the Semiscale Core, TREE-NUREG-1073 (Märch 1977).

6. J. M. Cozzuol et al, Semiscale Test S-02-8 Mini-Topical for Standard Problem Five, TREE-NUREG-1015 (November 1976).

7. E. M. Feldman and D. J. Olson, Semiscale Mod-1 Program and System Descriplion for the Blowdown Heat Transfer Tests (Test Series 2), ANCR-1230 (August 1975).

8. B. L. C'ollins, H. S. Crapu, K. E. Sackott, Experiment Data Repurt for Semiscalc Mod-1 Test 3-02-6 (Blowdown Heat 7'ransfer Test), TREE-NUREG-1037 (January 1977).

9. H. S. Crapo ct al, Experiment Data: Report. for Semiscale Mod-1 Test S-02-4 (Blowdown Heat.Transfer 'l'est), ANCR-1234 (November 1975). 
APPENDIX A

STEAM GENERATOR RESPONSE 
THIS PAGE

\section{WAS INTENTIONALLY LEFT BLANK}




\section{APPENDIX A \\ STEAM GENERATOR RESPONSE}

The effect of the steam generator heat transfer on the system blowdown behavior for the small break is of concern due to the length of time required for a complete blowdown. This section presents the results of an analysis of the data pertaining to the response of the steam generator during blowdown for Test S-02-6.

The steam generator was instrumented with four metal and four secondary fluid thermocouples paired to provide an indication of the heat transfer to the primary fluid during blowdown. The steam generator configuration and instrumentation locations are shown in Figure A-1.

The temperature histories measured by the secondary material and secondary fluid thermocouples provide a mechanism by which to analyze the steam generator thermal performance. The measured secondary fluid temperatures (TFU-SG1, and TFU-SG4) and the secondary material temperatures (TMU-SG1, TMU-SG2, and TMU-SG4) obtained during Test S-02-6 are shown in Figures A-2 and A-3, respectively. Calculations were performed to evaluate the heat transfer from the steam generator during Test S-02-6. The calculation entailed a simple energy balance using the steam generator tube bundle metal and secondary side fluid that is surrounding the tubes as the control volume. The change in the external steam generator structure energy state and external heat losses were neglected. An estimate of the secondary side fluid volume that was capable of transferring a significant amount of heat to the tubes was assumed sufficiently large such that the calculated heat transfer was regarded as a maximum probable value. The results indicate an average energy transfer of $7374 \mathrm{Btu}$ from the secondary to the primary side between 72 and $600 \mathrm{sec}$ after rupture. However, a similar energy balance between the time of rupture and $72 \mathrm{sec}$ indicates the primary side fluid transferred $6800 \mathrm{Btu}$ of energy to the secondary side. These results imply a net energy exchange to the primary side of only $574 \mathrm{Btu}$ which represents about $2 \%$ of the energy initially stored in the primary system fluid. The small net energy exchange is a consequence of the length of time $(72 \mathrm{sec})$ that the primary fluid transferred energy to the secondary side due to the slow depressurization of the system. The primary to secondary energy exchange is illustrated in Figure A-4, by the fact that TSU-6 and TFU-8 are higher in temperature than TFU-SGl and TFU-SG4 until $72 \mathrm{sec}$. Prior to $72 \mathrm{sec}$ the energy exchange process from the primary side to the secondary side was complicated by the venting of steam by a relief valve in the secoindary side of the steam generator. Due to venting, the turnaround point (energy transfer from secondary side to primary side instead of from primary side to secondary slde) shown to occur at $40 \mathrm{sec}$ in Figure A-2 did not actually occur until $72 \mathrm{sec}$, as indicated in Figure A-4. The decrease in temperature of the secondary side fluid between 40 and $72 \mathrm{sec}$ while the primary side was still transferring energy to the secondary side implies that the secondary side was losing energy by venting during this period. 


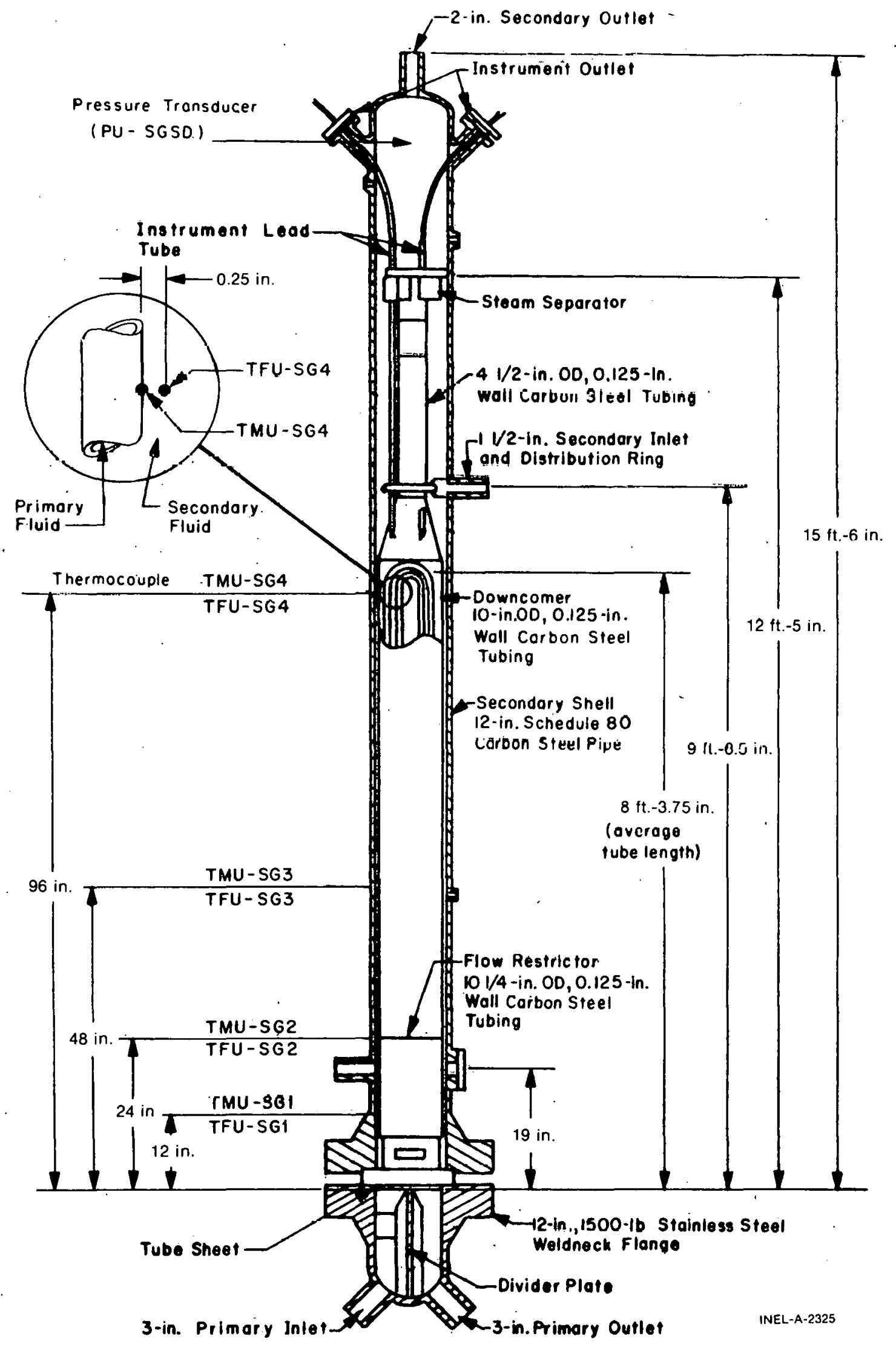

Fig. A-1 Intact loop steam generator configuration. 


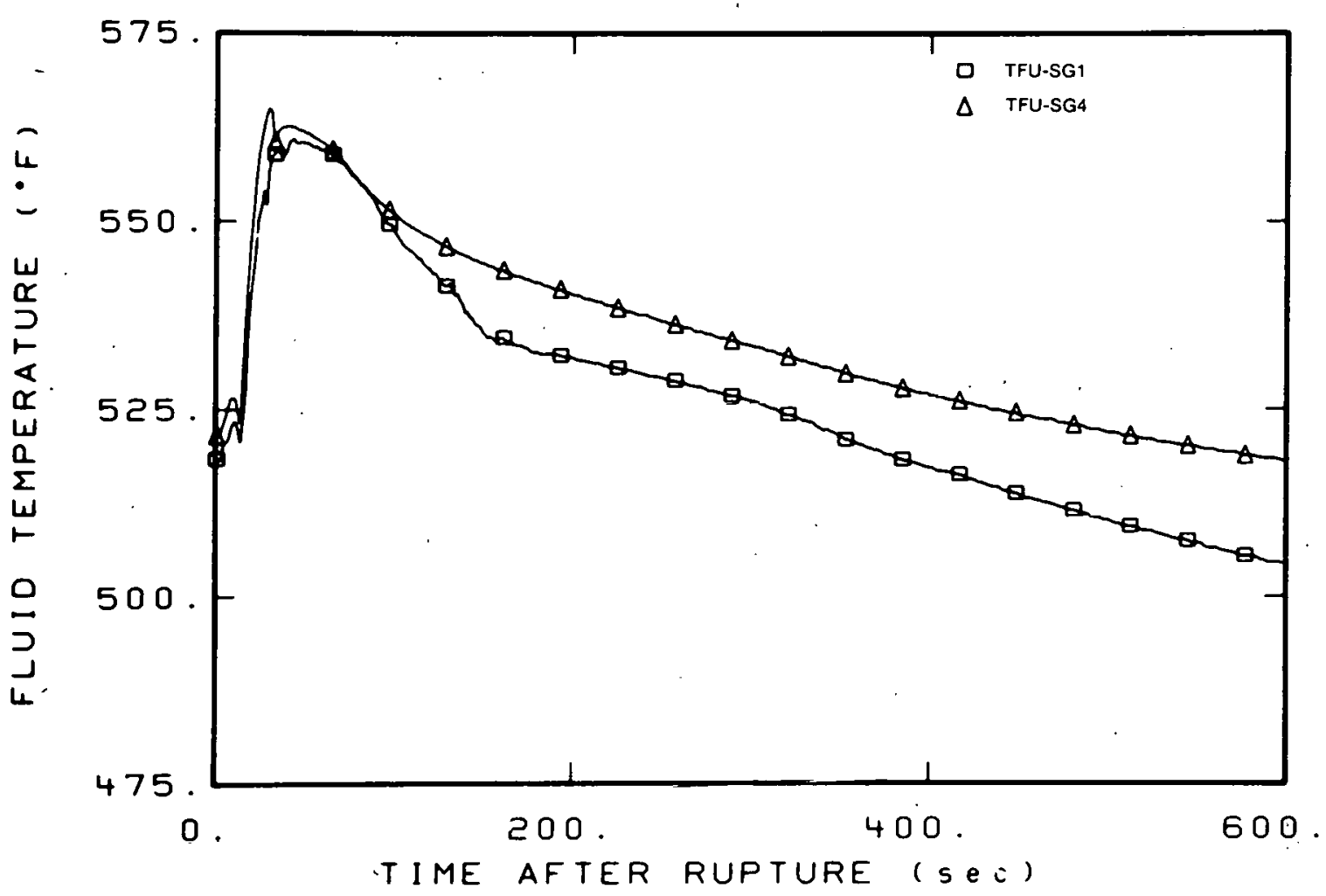

Fig. A-2 Steam generator secondary side fluid temperatures - Test S-02-6.

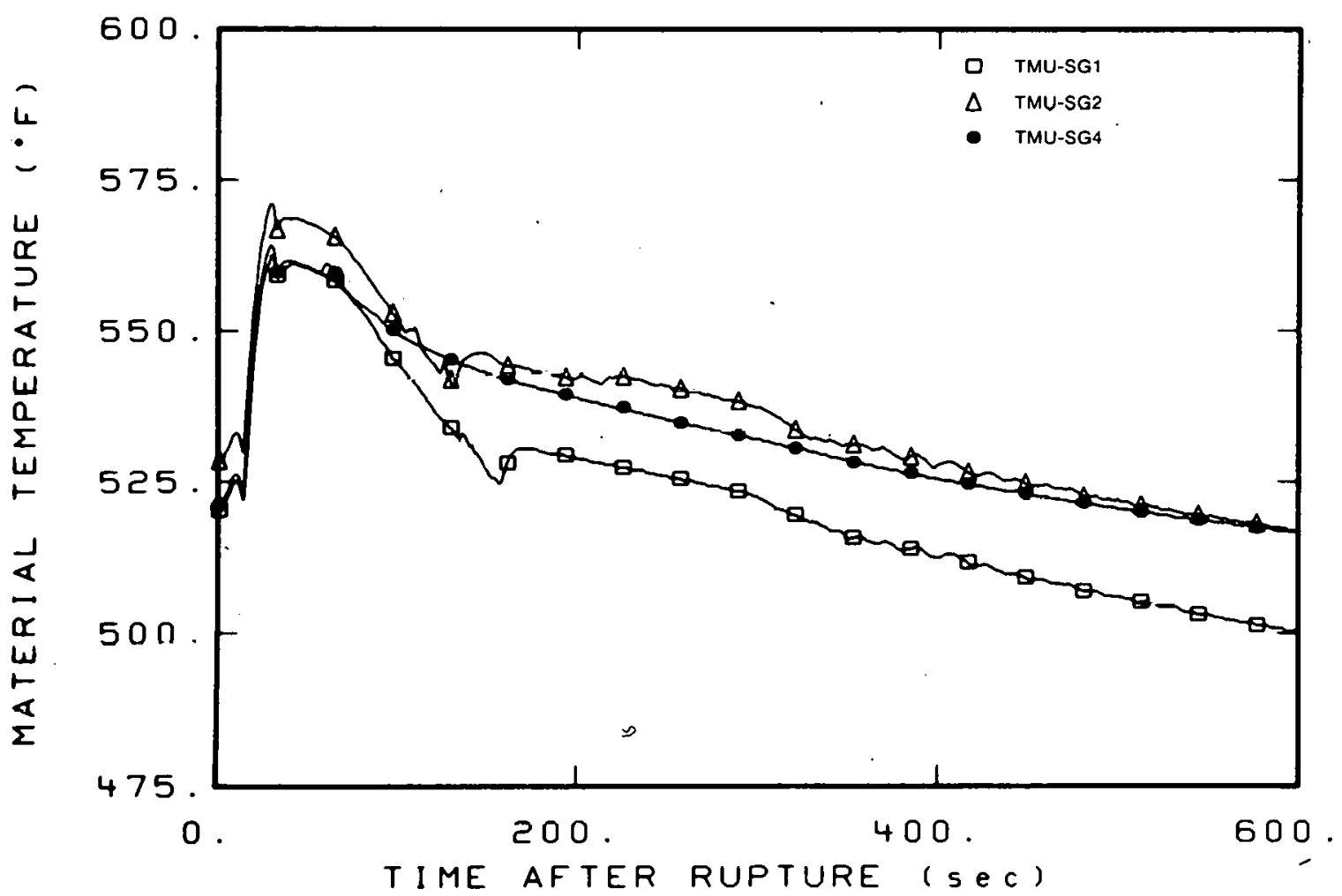

Hig. A-3 Sléam generator cecondary side ute lal temperatures - Test S-02-6. 


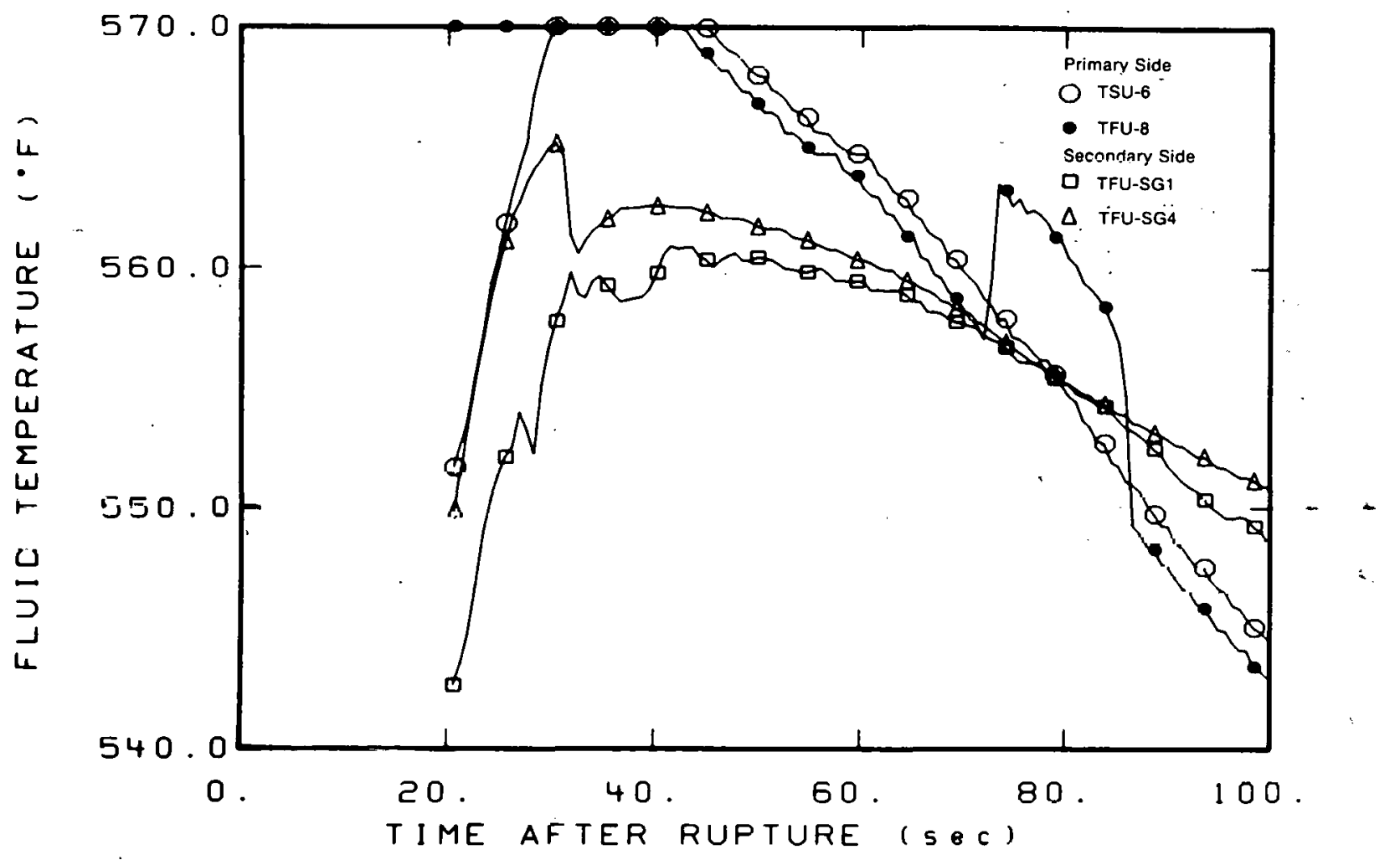

Fig. A-4 Steam generator primary and secondary side fluid temperatures - Tcst S-02-6.

Because of simultaneous energy exchange into and out of the secondary side, determination of the steam generator heat transfer is almost impossible, especially will the limitcd instrumentation used on the secondary side. The energy exchangc values quoted. earlier are, therefore, gross estimales and should be viewer in that perspeclive. Ncvertheless, the preceding analysis indicates that a relatively small amount of net energy was transferred from the steam generator secondary to the primary fluid for the small break compared with the overall initial amount of internal energy contained in the primary fluid prior to rupture. 
APPENDIX B

PIPING HEAT TRANSFER 
THIS PAGE

WAS INTENTIONALLY

LEFT BLANK 


\section{APPENDIX B}

\section{PIPING HEAT TRANSFER}

Piping heat transfer can affect the quality, velocity, and temperature of the primary fluid during the Semiscale Mod-1 blowdown transient. Piping heat transfer during Test S-02-6 has been evaluated to determine its dependence on azimuthal position in the pipe section during a slow depressurization of the system.

The piping wall heat fluxes were determined for the small break test from the observed temperature histories provided by thermocouples installed within the material of the piping walls in both the intact and broken loops. The inverse heat conduction problem was solved through use of a computer program, INVERT ${ }^{[a]}$. The measured pipe metal temperatures were input into INVERT to deduce the heat transfer rates and the pipe inner wall temperatures as functions of time. The heat transfer rates and calculated inner wall temperatures were then used in conjunction with the measured fluid temperatures to deduce average heat transfer coefficients existing at given locations as functions of time. An error analysis of the INVERT method including experimental errors as applied to data similar to the Semiscale Mod-1 data is presented in Reference B-1.

Figure B-1 shows the surface heat flux values calculated for the cold legs of the intact and broken loops. The curves include heat fluxes calculated from thermocouples located at the top and bottom of Spool Pieces 15 and 20. The surface heat flux is seen to be negative for the first $40 \mathrm{sec}$ after rupture (prior to the pump stopping) indicating the fluid temperature is greater than the pipe wall temperature. The fluid temperature following rupture riscs due to the blowdown mixing proccsscs of the superhealed fluid coming from the intact loop hot leg. The in tact loop cold leg fluid temperature continues to rise until the pressure due to depressurization causes saturation conditions to exist. The stratification exisiting at the vessel inlet, shown in Figure B-2, from $120 \mathrm{sec}$ to the time of ECC injection $(29.0 \mathrm{sec})$ causes the surface heat flux at the bottom of the Spool Piece 15 to be about three times as large as that at the top of the pipe. The time of ECC injection is clearly illustrater in Figure B-1 as the surface heat flux rises sharply at $290 \mathrm{sec}$ due to the subcooled ECC injected. A similar but less severe rise occurs at $340 \mathrm{sec}$ at Spool Piece 20 as the ECC fluid reaches that location on its way to the break.

Integrating the heat flux over the time of the test $(0$ to $600 \mathrm{sec})$ results in an energy level for the intact loop cold leg that is about $10 \%$ of the prerupture fluid energy. The surface heat flux for the small break at Station 15 was compared with the heat flux calculated at the samc location for a large hreak ${ }^{[B-2]}$. Comparison of the surface heat flux values led to the conclusion that the small break results in more piping heat transfer than does the large break, and, therefore, results in a larger percentage of the total energy being lost nut the break in the Semiscale systcm.

[a] For the purpose of historical configuration control, INVERT is referenced as program numbcr II00086IB. 


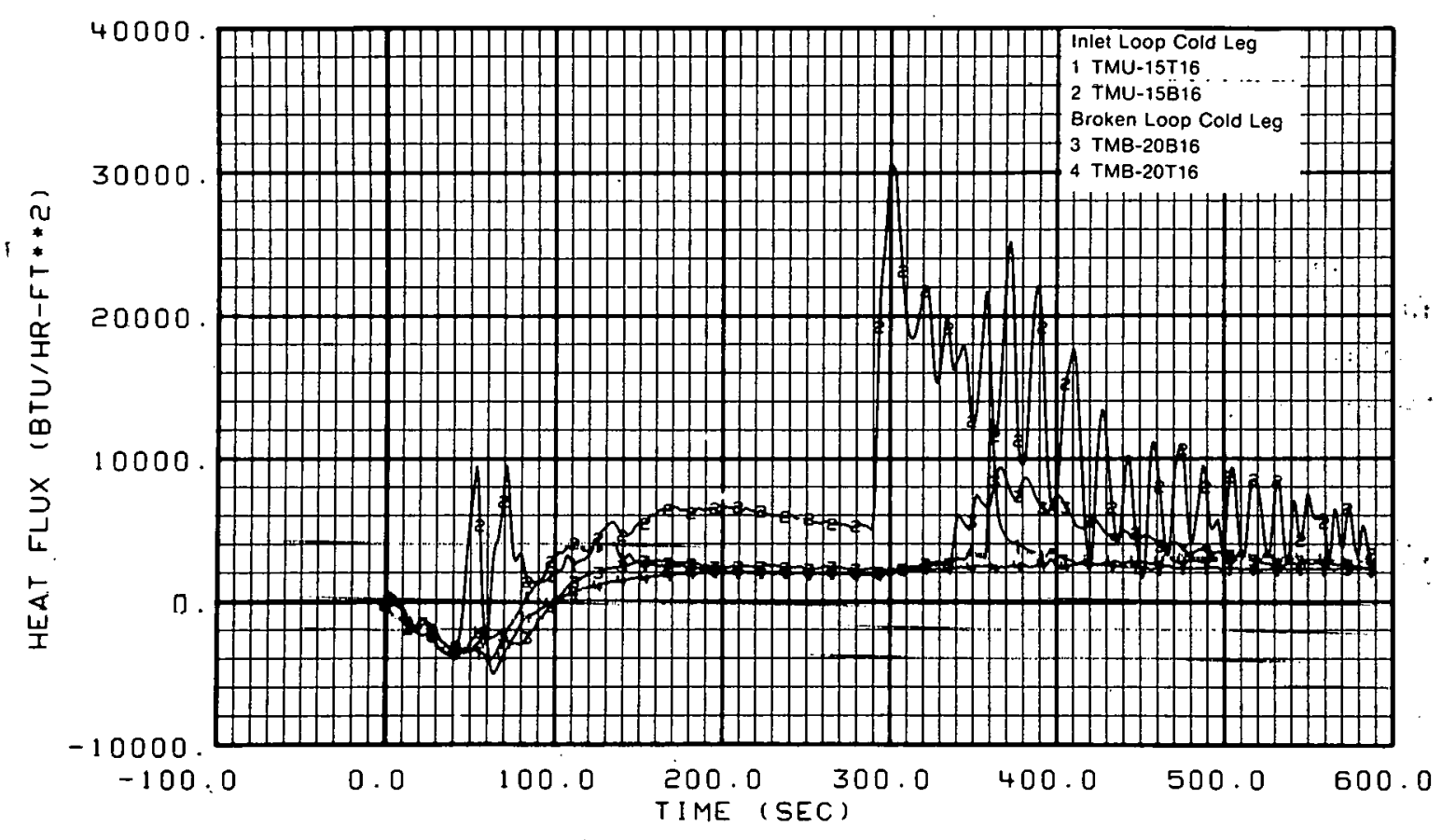

B-1 Intact and broken loop cold leg surface heat fluxes - Test S-02-6.

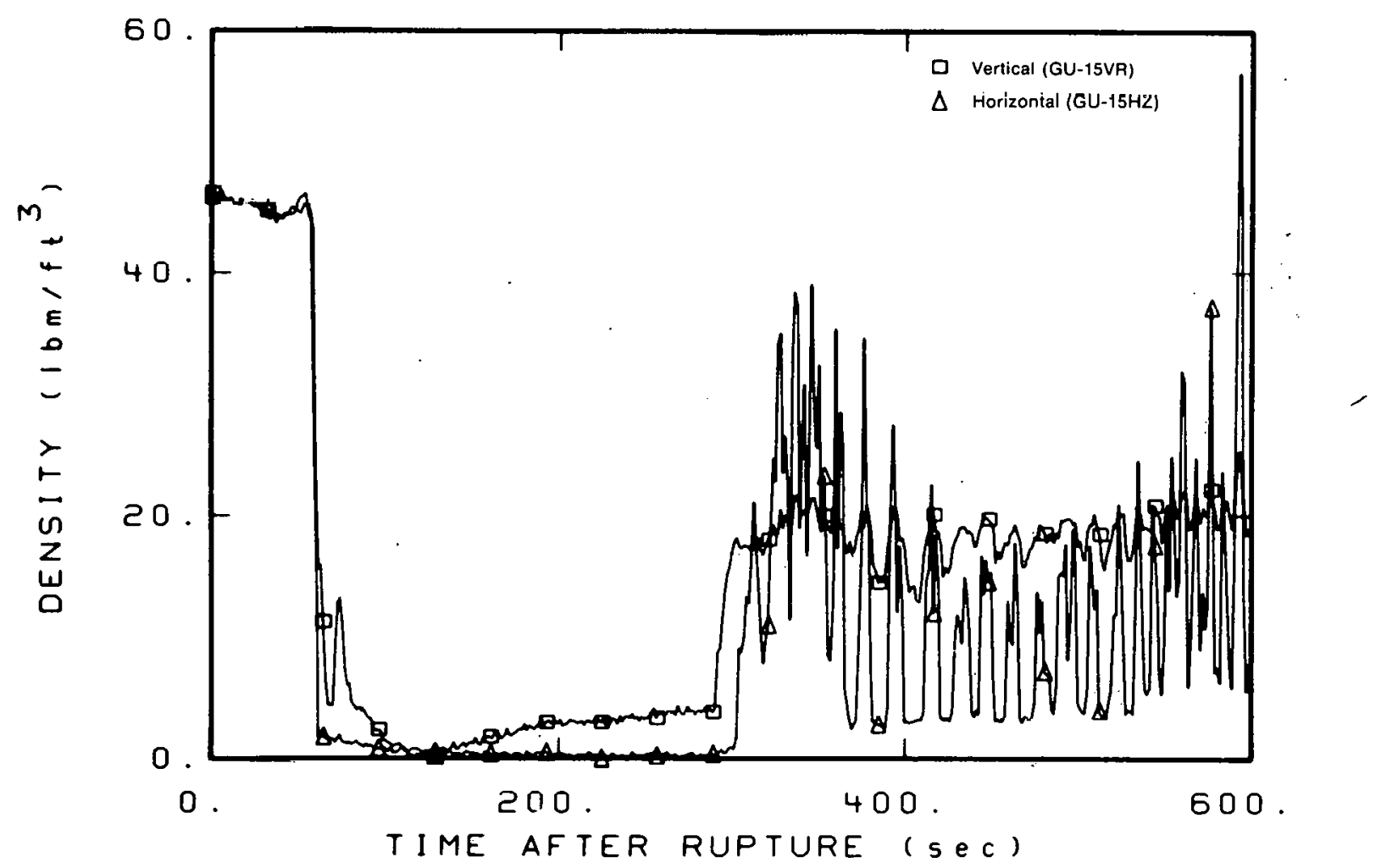

B-2 Vertical and horizontal fluid densities in instrument Spool 15 - Test S-02-6. 


\section{REFERENCES}

B-1. D. J. Hanson et al, ECC Performance in the Semiscale Geometry, ANCR-1161 (June 1974).

B-2. R. T. French, An Evaluation of Piping Heat Transfer, Piping Flow Regimes and Steam Generator Heat Transfer for the Semiscale Mod-1 Isothermal Tests, ANCR-1229 (August 1975). 
DISTRIBUTION RECORD FOR TREE-NUREG 1056

Internal Distribution

- 1 - Chicago Patent Group 9800 South Cass Avenue

Argonne, IIIinnis 60439

2 - CA Benson

Idaho Operations office-ERDA

Idaho Falls, ID 83401

3 - RJ Beers, ID

4- PE Litteneker, ID

5 - RE Tiller, ID

6 - RE Wood, ID

7 - HP Pearson, Supervisor Technical Information

8-17 - INEL Technical Library

18-75 - Special Internal

76-95 - Authors

External Distribution

96-97 - Saul Levine, Director Office of Nuclear Regulatory Research, NRC Washington, DC 20555

98-115 - Special External

116-420 - Distribution under NRC-2, Water Reactor Safety Research Fuel Behavior 